\title{
In Vitro Metabolism and Bioavailability Tests for Endocrine Active Substances: What is Needed Next for Regulatory Purposes?
}

\author{
Miriam N. Jacobs ${ }^{1}$, Susan C. Laws ${ }^{2}$, Kate Willett ${ }^{3}$, Pat Schmieder ${ }^{4}$, \\ Jenny Odum ${ }^{5}$, and Toine F. Bovee ${ }^{6}$
}

${ }^{1}$ Scientific Committee and Emerging Risks Unit, European Food Safety Authority, Parma, Italy; ${ }^{2}$ Endocrinology

Branch (MD-72), Toxicity Assessment Division, National Health and Environmental Effects Research Laboratory, US EPA, Research Triangle Park, NC, USA; ${ }^{3}$ The Humane Society of the United States, Washington, DC, USA; ${ }^{4}$ Mid-Continent Ecology Division, National Health and Environmental Effects Research Laboratory, US EPA, Duluth, MN, USA; ${ }^{5}$ Regulatory Science Associates, Dunoon, Argyll, UK; ${ }^{6}$ RIKILT - Institute of Food Safety, Wageningen University and Research Centre, Wageningen, The Netherlands

\section{Summary}

Legislation and prospective legislative proposals internationally (may) require that chemicals be tested for their ability to disrupt the hormonal systems of mammals. Chemicals found to test positive in vitro are considered to be endocrine active substances (EAS) and may be putative endocrine disruptors (EDs) in vivo. While there is a growing body of international in vitro test guidelines addressing EAS mechanisms and modes of action, to date there are still few or no standardized methods to incorporate metabolic and toxicokinetic aspects into these in vitro tests for EAS. In vitro assays for EAS should incorporate metabolic enzyme systems to better address the relevance of EAS tests to in vivo adverse outcome pathways, and a previous OECD review paper indicated how this could be done. This paper revisits those recommendations, addressing where research and funding efforts are needed to expedite the development of suitable in vitro metabolism systems to improve the accuracy of in vitro assays for identifying EAS and EDs. Recommendations are made for projects to support short, medium, and long-term goals. The complexity of in vivo metabolism presents major challenges for the development of predictive models suitable for the extrapolation of data from in silico/in vitro approaches to models that can occur in vivo. Therefore, the long-term recommendations are intended to foster an international harmonization of databases, delineation of metabolic pathways, and development of predictive tools that will provide a fundamental understanding of the processes by which metabolism occurs, increasing the predictive accuracy of in silico/in vitro methods.

Keywords: regulatory testing, metabolism, endocrine active substances, alternative methods

\begin{abstract}
Abbreviations
A, androgen; AGD, anogenital distance; AhR, aryl hydrocarbon receptor; AOP, adverse outcome pathway; AR, androgen receptor; BPA, bisphenol A; CAR, constitutive androstane receptor; CYP, cytochrome P450; DAR, Draft Assessment Report (EU); DER, Data Evaluation Record (US and Canada); DHEA, dehydroepiandrosterone; DRP, Detailed Review Paper; E, estrogen; EAS, endocrine active substances; EURL ECVAM, EU Reference Laboratory ECVAM; ED, endocrine disruptor; EDSP, US EPA's Endocrine Disruptor Screening Program; EDTA-AG, OECD Endocrine Disruptor Testing and Assessment Advisory Group; ENDOMET, EU $5^{\text {th }}$ framework project "Dysregulation of endogenous steroid metabolism potentially alters neuronal and reproductive system development: effects of environmental plasticisers"; ER, estrogen receptor; GD, Guidance Document; GR, glucocorticoid receptor; HPG, hypothalamic-pituitary-gonadal axis; HPTE, 2-bis(p-hydroxyphenyl)-1,1,1-trichloroethane; JaCVAM, Japan Centre for the Validation of Alternative Methods; ICCVAM, Interagency Coordinating Committee on the Validation of Alternative Methods; ITS, integrated testing strategy; Log Kow, octanol-water partition coefficient; MIE, molecular initiating event; mRNA, messenger RNA, NADPH, reduced form of nicotinamide adenine dinucleotide phosphate, OECD, Organisation for Economic Cooperation and Development; PBTG, performance based test guideline; PHS, prostaglandin $\mathrm{H}$ synthase; PPAR, peroxisome proliferator activated receptor(s); PR, progesterone receptor; PXR, pregnane $\mathrm{X}$ receptor; RAR, retinoic acid receptor; RXR, retinoic $\mathrm{X}$ receptor; RCBA, recombinant cell bioassay; S, steroidogenesis; S9, supernatant product of an organ tissue homogenate used in biological metabolism assays; SOP, standard operating protocols; StAR, steroidogenic acute regulatory protein; STTA, stably transfected transactivation assay; SULT, sulfotransferase; PAPS, 3'-phosphoadenosine-5'-phosphosulphate; PBTK, physiologically based toxicokinetic modelling; QSAR, Quantitative Structure Activity Relationship; T, thyroid; T3, triiodothyronine; T4, thyroxine; TIM, TNO gastro-intestinal tract model; TG, Test Guideline; TR, thyroid receptor; T-Screen, thyroid receptor-screen; TOFMS, time-of-flight mass spectrometry; UGT, UDP-glucuronosyltransferases; UNEP, United Nations Environment Programme; UPLC, ultra-performance liquid chromatography; VMG-NA, OECD's Validation Management Group-Non Animal; VTG, vitellogenin; WHO, World Health Organisation; YAS, yeast androgen screen; YES, yeast estrogen screen
\end{abstract}

Received October 5, 2012; accepted in revised form February 20, 2013 


\section{Introduction}

One of the most frequently cited limitations of in vitro assays concerns the qualitative and quantitative deficiencies in the metabolism of test chemicals in comparison with in vivo assays. These and related deficiencies are particularly important considerations when testing endocrine active substances (EAS), since several hormonally active chemicals, including some that occur naturally, are known to require bioactivation. Previous work has highlighted those problems and concluded that some of the necessary tools for incorporating an assessment of metabolism into toxicity testing approaches were already available and sufficiently well characterized and developed to meet practical regulatory requirements (Jacobs et al., 2008; OECD, 2008). However, five years later, no such tests are under consideration for (pre)validation through the European, US, or Japanese validation bodies (EURL ECVAM, ICCVAM, JaCVAM).

The use of in vitro models to better prioritize chemicals for further testing, to advance the use of in vitro tests for directing testing that is more targeted for specific endpoints, and to move towards an eventual replacement of in vivo tests with in vitro are hampered by insufficient knowledge on chemical metabolism, bioactivation, and bioavailability. At this point in time, approaches for evaluating in vitro metabolism cannot be used to qualitatively or quantitatively predict (de)toxification that may occur in vivo, although these in vitro metabolism methods can provide valuable insights. A critical initial aspect of the incorporation of metabolizing systems is to ensure that no potentially active metabolites are missed during in vitro assessment. In addition, it is important to understand the metabolic capacity of a given in vitro system so that the results will be better understood.

The purpose of the current paper is to encourage the inclusion of the assessment of metabolism, particularly human metabolism, in in vitro assays designed to evaluate chemicals for endocrine activity and bioactivation. Practical recommendations are provided for short, medium, and long-term projects designed to achieve the integration of metabolism into EAS in vitro testing. In vitro digestion and bioavailability models also are reviewed briefly.

Any of the metabolizing systems would need to be assessed for reliability and relevance in accordance with validation principles with respect to its use in each EAS assay. Test method validation is a process based on scientifically sound principles by which the reliability and relevance of a particular test, approach, method, or process is established for a specific purpose. ${ }^{1}$

\section{Background}

\subsection{OECD DRP 97 (OECD, 2008)}

In 2008, the Organisation for Economic Cooperation and Development (OECD) published a Detailed Review Paper (DRP) on the use of metabolizing systems for in vitro testing of endocrine active substances (EAS) for international regulatory purposes (OECD, 2008; Jacobs et al., 2008). The focus of this review paper was to assess how in vitro tests for EAS could mimic reallife metabolism scenarios more accurately and appropriately. The aim also was to advance regulatory toxicity testing, particularly with regard to improving the quality and predictive capacity of in vitro toxicity testing, reducing animal testing, reducing costs, and advancing $21^{\text {st }}$ Century Toxicity Testing (NAS, 2007) and integrated testing strategies (ITS) as part of the chemicals policy for the European Union (EU). The DRP, authored by an international group of experts and endorsed by the OECD membership, took several years to develop.

In essence, the review demonstrated that some of the necessary tools for incorporating an assessment of metabolism into toxicity testing approaches were already available and characterized well enough to be developed beyond the typical pharmaceutical and research applications to meet practical regulatory needs (OECD, 2008). The DRP 97 provided background on testing for EAS/ED ${ }^{2}$, the available test methods, and the role of mammalian metabolism in the activation and inactivation of both endogenous and exogenous steroids. The available types of systems for evaluating metabolic activity were compared and the potential problems for incorporating each system into in vitro tests for EAS, and how these might be overcome, were discussed. Lastly, recommendations were included for short, medium, and long- term activities that could lead to the validation and effective use of metabolizing systems in EAS/ED testing paradigms.

The metabolism DRP 97 (OECD, 2008; Jacobs et al., 2008) discussed several approaches that could be utilized for the assessment of metabolism in EAS screening, including a tiered approach that would add metabolism prediction models and in vitro metabolism tests to tiered batteries of EAS tests, combined testing where in vitro metabolism tests are paired with individual in vitro EAS tests, and a screening approach in which chemicals would be screened for metabolism using prediction models and in vitro approaches prior to EAS testing. The DRP concluded that "Although the ideal solution for the simultaneous testing of [endocrine disrupting] potential and metabolism may not be

\footnotetext{
1 The "Solna Principles of Validation," agreed upon at an OECD workshop in Solna, Sweden in 1996, are provided in the OECD Guidance Document no. 34, on the Validation and International Acceptance of New or Updated Test Methods for Hazard Assessment (OECD, 2005), and these apply to the validation of new or updated test methods for hazard assessment, whether they are in vivo or in vitro, or tests for effects on human health or the environment.

2 In the context of the OECD Guidance Document 150 on Standardised Test Guidelines for Evaluating Chemicals for Endocrine Disruption (OECD, 2012a), an endocrine disrupter (ED) has been defined according to WHO (2002), i.e., "An ED is an exogenous substance or mixture that alters function(s) of the endocrine system and consequently causes adverse health effects in an intact organism or its progeny or (sub) populations." WHO (2002) also defines the term "potential ED" such that "A potential endocrine disruptor is an exogenous substance or mixture that possesses properties that might be expected to lead to endocrine disruption in an intact organism or its progeny or (sub)populations." It is acknowledged that many other definitions exist (e.g., Weybridge Conference, 1996), but the WHO (2002) definition has been used as a working definition for the GD document because it covers both human health and wildlife populations. This widely used, but not universally accepted definition is also used in this paper. Furthermore, for the purposes of the GD, it was agreed by the EDTA-AG to operationally define the term "possible ED" to mean a chemical that is able to alter the functioning of the endocrine system but for which information about possible adverse consequences of that alteration in an intact organism is uncertain (OECD, 2012a).
} 
reached in the near future, this should not prevent the use of the best possible combination of tests that are already available..." and made the following recommendations:

- Cell lines used in existing EAS assays should be characterized with respect to endogenous metabolic capacity.

- The utility of combining clearly defined digestion models with existing EAS assays should be explored.

- The utility of combining S9 fractions with existing EAS assays should be explored.

- The feasibility of expressing Phase I and II metabolic enzymes in engineered cell lines should be explored, as well as the importance of combining Phase I and Phase II enzymes.

- There should be an investigation into the relevance of using the prostaglandin $\mathrm{H}$ synthase (PHS) system for metabolizing EASs.

- Approaches should be developed that can predict systemic exposure, i.e., in vitro to in vivo extrapolation.

- (Q)SARs should continue to be explored and developed for the analysis of potential endocrine effects through well specified mechanisms (e.g., receptor activation) for the analysis of potential interference with the metabolism of endogenous hormones and exogenous compounds, as well as for the prediction of metabolism of chemicals by phase I and II enzymes.

As already indicated, there has been relatively little progress addressing these recommendations for regulatory purposes (other than for pharmaceutical applications) over the past five years. On the other hand, several in vitro screening tests for EAS have been validated by the OECD Validation Management Group Non Animal (OECD VMA-NA) and US EPA's Endocrine Disruptor Screening Program (US EPA EDSP).

\subsection{The importance of metabolism in prediction of response}

One of the targets of $21^{\text {st }}$ Century Toxicity Testing (NAS, 2007) is to move to a greater use of in vitro approaches to predict hazard to the health of humans and wildlife. One of the most frequently cited limitations of in vitro assays without metabolic capacity concerns the qualitative and quantitative deficiencies in the metabolism of test chemicals, in comparison with in vivo metabolism. In an in vitro assay, with or without metabolic activation, the results are only the same if the parent compound is active and not metabolized, or if the metabolite formed is as active as the parent compound. In addition, differences in the metabolic capacities among in vitro assays may result in different outcomes that when left unexplained, can lead to confusing interpretations when making comparisons across assays. This is a particularly important consideration when testing EAS, since several hormonally active chemicals, including some naturally occurring EAS, are known to be subject to bioactivation. Thus false negative ${ }^{3}$ data could arise, if the required metabolic processes for activation are lacking in the in vitro system being used.

It is important to note that comparing assays with and without metabolic capability could result in a variety of responses. For example, there might be no significant difference in the observed results between the two assays because the range for the effective concentrations of the parent chemical remains the same and activates a similar response in both cases. Alternative$1 y$, if a parent chemical is weakly active but is metabolized to a form that has 10 times more potency, then the addition of metabolic capability to an assay may shift the response curve closer to that presented by a positive control. Some examples of this for estrogen receptor modulators are tamoxifen metabolized to hydroxy-tamoxifen and methoxychlor metabolized to 2-bis(phydroxyphenyl)-1,1,1-trichloroethane (HPTE). Conversely, a chemical that is apparently inactive in an in vitro assay without metabolism may be metabolized to an active form. Finally, a parent chemical that is somewhat active may undergo extensive metabolism in the in vitro system such that its concentration is reduced sufficiently to result in a reduction or total elimination of any activity observed in an assay without metabolism.

Another consideration is that metabolic differences also exist between species. A chemical that is bioactivated in an in vitro assay incorporating metabolism from one species may not be activated in an organism lacking the same metabolic capability represented in the in vitro assay. In this case, the in vitro effect cannot be considered to be a false positive but rather can be explained as a species difference.

It is well established that information on the metabolism of a substance is important when evaluating its toxic potential. The liver is usually the primary site of metabolism, but extra-hepatic tissues may play a significant role. The enzymes of xenobiotic metabolism have been divided into Phases I and II. The former involves oxidation of the parent molecule, e.g., by the mixed function oxidase activities of the many isoforms of the cytochrome P450 (CYP) family of enzymes. Phase II metabolism involves the conjugation of metabolites generated by oxidation

\footnotetext{
3 In the context of OECD Guidance Document 34 on the validation and international acceptance of new or updated test methods for hazard assessment (OECD, 2005), the definitions of controls, false positives, and false negatives are as follows; "Concurrent controls (negative, solvent/vehicle, and positive), as appropriate, serve as an indication that the test method is operative under the test conditions and provide a basis for experiment-to-experiment comparisons; they are usually part of the acceptance criteria for a given experiment. The acceptable ranges for the control responses and historical data used to establish the acceptable range should be included." The positive control for EAS in vitro studies is generally the endogenous ligand, e.g., 17ß estradiol for estrogen receptor (ER) assays. The negative control is a compound with another mode of action, e.g., a corticosteroid for ER assays. The solvent or vehicle control is the solvent or vehicle in which the test chemical is tested, often dimethylsulfoxide (DMSO), water or ethanol. "False negative: A substance incorrectly identified as negative or non-active by a test method, when in fact it is positive or active. False negative rate: The proportion of all positive substances falsely identified by a test method as negative. It is one indicator of test method performance.

False positive: A substance incorrectly identified as positive or active by a test, when in fact it is negative or non-active. False positive rate: The proportion of all negative (non-active) substances that are falsely identified as positive. It is one indicator of test performance. Per definition, false positive data could be generated due to the lack of metabolic detoxification of test chemicals, and false negative data could arise if the required metabolic processes for activation are lacking in the in vitro system used. However, a chemical tested positive in vitro, but rapidly inactivated in vivo, may still be true positive, as in an organism lacking the metabolism of the test animal, the effect of the non-metabolized parent chemical is highly relevant" (OECD, 2005).
} 
reactions in Phase I to water soluble entities, e.g., glucuronidation and sulfation. In extra-hepatic tissues metabolism may differ from that which occurs during hepatic metabolism. The prostaglandin $\mathrm{H}$ synthase (PHS) system is particularly active and oxidizes a wide range of xenobiotics, although extra-hepatic mixed function oxidases have also been shown to metabolize a number of chemicals (Bernauer et al., 1999, 2000, 2002, 2003).

The timing and amount of metabolite formed (dependent on enzymatic rate and capacity), as well as the location of metabolite formation with respect to the subcellular location of the biomolecules that a chemical may interact with, are all factors that contribute to whether or not the metabolism is an activation or detoxifying process. Most chemicals are metabolized and conjugated, resulting in more polar forms that are partitioned to aqueous phases within the body and excreted. However, the question is whether they remain at a "target" location in the body long enough and in sufficient concentration to initiate an effects pathway prior to their further metabolism and elimination. In vitro assays can be used to gain the mechanistic understanding of the chemical form, parent and/or metabolite, likely responsible for an observed effect.

In addition to xenobiotics, endogenous steroids are extensively metabolized by Phase I and II enzymes in both the liver and their target tissues. Metabolism may lead to the inactivation of endogenous steroids and will affect the ability of the cells to perform their normal functions. Thus, exogenous compounds that induce de novo synthesis of Phase I and II enzymes can ultimately alter the availability of natural hormones and thereby cause endocrine disrupting effects. Specific assays have been developed to detect compounds that modulate steroidogenesis, ranging from an inhibition of a specific enzyme (e.g., aromatase; Cunat et al., 2005), to an induction or inhibition of enzymes at multiple sites within the steroidogenic pathway (e.g., H295R steroidogenesis assay, Hecker et al., 2007; OECD TG 456, OECD 2011a).

Metabolizing systems for use in vitro can be either sub-cellular (e.g., enzyme homogenates, S9, cytosol, or microsomes) or cellular components (e.g., the residual metabolism of the indicator cells themselves, metabolically competent primary cells such as hepatocytes, genetically-engineered cell lines, or engineered tissues). S9 mix is the supernatant fraction obtained from an organ (usually rat liver) homogenate by centrifuging at 9000 $\mathrm{g}$ for 20 minutes in a suitable medium; this fraction contains cytosol and microsomes. The microsomal component of the S9 fraction contains cytochrome P450 isoforms (Phase I metabolism), UDP-glucuronosyltransferases (phase II metabolism) and other enzyme activities. The cytosolic portion contains the major part of the activities of other transferase enzymes (phase II metabolism).

Despite the fact that there are several technical problems with using sub-cellular metabolizing systems in assays for testing EAS (such as non-specific binding to protein, potential toxicity to target cells), there is sufficient evidence in the literature to show that these limitations can be overcome and that the presence of such enzymes can modulate the chemical toxicity of several types of EAS (e.g., Taxvig et al., 2011). Furthermore, the data generated can be used to inform the metabolism param- eters and interspecies extrapolations for physiologically based toxicokinetics (PBTK) models in chemical risk assessment (Andersen, 2003; Clewell and Clewell, 2008), that can allow extrapolation of in vitro concentration response curves to in vivo dose response curves (Punt et al., 2011).

Recent efforts also have focused on standardizing in vitro S9 systems to measure metabolism in fish species (Johanning et al., 2012). Related work to measure effects on chemical bioavailability in these systems has been shown to be an important component of improving predictions of in vivo metabolism (Escher et al., 2011). It had been demonstrated previously that components within in vitro systems can affect chemical bioavailability and should be considered when interpreting the results from EAS assays (Heringa et al., 2004). Incorporating these new approaches will allow the effects of bioavailability and metabolic transformation to be determined along with the major effect under study in EAS in vitro assays.

Many cell-based assays for EAS may have some inherent ability to metabolize xenobiotics. This should be investigated in order to accurately interpret results from the assays, and when considering whether or not to add a supplementary metabolizing system to a cell-based assay. Examples of suitable candidates of in vitro assays that could benefit from the incorporation of metabolism systems include the estrogen (OECD TGs 455 and 457), androgen, and thyroid receptor-mediated transcriptional activation assays, and the H295R assay for steroidogenesis (OECD TG 456) (OECD, 2006, 2011a, 2012a,b,c). These assays either have been incorporated into guidelines or are in common use in research laboratories throughout the world. The metabolic capability of some of these assays has been preliminarily characterized already (e.g., the steroidogenesis assay based on the H295 adrenocortical carcinoma cell line, and the ER $\alpha$-CALUX based on the T47D breast cell line (DesdoitsLethimonier et al., 2012; Hoogenboom et al., 2001), although the latter had stability and transferability problems until very recently (van der Burg et al., 2010)).

In some cases, it may be advantageous to use a cell line without metabolic capability so that any observed effects can be unequivocally ascribed to the chemical under test rather than potential metabolites. In this respect, since yeast have no, or only very limited, metabolic capacities (Bovee et al., 2006, 2008a,b, 2010), yeast based assays in which hormone receptors from a variety of species can be inserted along with reporter genes, may provide a comparative advantage for screening for EAS by providing clear information on hormone receptor activation due to a parent compound. Moreover, although identified as suffering from limitations such as problems with materials that have fungicidal activity or inhibit cell proliferation, solubility, permeability, or transport issues across the cell wall (ICCVAM, 2003), the yeast cell wall has been demonstrated previously to be easily permeable for compounds with a molecular weight up to 620 , and the flexibility of the wall of living cells allows an easy passage of even larger molecules (De Nobel and Barnett, 1991; Scherrer et al., 1974; Van der Rest et al.,1995). In addition, the OECD DRP No. 135 on "Environmental endocrine disruptor screening: The use of estrogen and androgen receptor binding and 
transactivation assays in fish" (OECD, 2010) describes yeast assays with the following recommendation:

"The YES/YAS-assays are recommended for further detailed evaluations primarily focusing on assays with fish steroid hormone receptors. It should be further evaluated whether such tests can provide meaningful information with special emphasis towards fish. Detailed comparisons on advantages/disadvantages to other in vitro assays, such as regarding yeast cell membrane permeability to certain compounds or chemical classes or other potential limitations, need to be clearly demonstrated before any further test method development or validation is performed. The sensitivity and specificity of any proposed YES/YAS assay needs to be demonstrated prior any further developments towards a Test Guideline."

However, each assay system has its own specific advantages and disadvantages in differing situations. In this regard yeast systems are useful to isolate a "pure ER mediated response" from one that might also include some residual metabolism such as from vertebrate cell systems (Bovee and Pikkemaat, 2009).

The YES and YAS assays (i.e., yeast estrogen screen and yeast androgen screen) are commonly used for testing environmental samples. If the sensitivity and specificity of these assays are adequate, they may eventually be included in performance based test guidelines (PBTG) as developed by the OECD VMG-NA.

More detailed guidance as to the advantages, disadvantages, or limitations of each in vitro metabolizing system is provided in the DRP 97 (OECD, 2008) and Jacobs et al. (2008), and information on the relevant in vitro validated endocrine screening assay OECD TGs, such as TG's 455, 456, and 457 (OECD, $2011 \mathrm{a}, 2012 \mathrm{~b}, \mathrm{c})$. How metabolizing systems for the assays can be used, and whether interchangeably or not, really depends upon the regulatory purpose. For regulatory pre-screening, there are instances where the metabolizing systems could be interchangeable, - but for more in depth weight-of-evidence for the mode of action, more definitive understanding of the adverse outcome pathway (AOP), research, and other purposes, these assays are not interchangeable, rather, they individually provide further biological mechanistic and mode of action information that, taken together, inform more holistically the biological networks in common with different taxa systems, as well as the differences.

\subsection{The importance of absorption in prediction of response}

Another complication when predicting hazard to human health using in vitro models is the unknown potential for absorption into the body. The main route for human exposure to EAS/EDs is oral (possibly via food). Only the fraction of chemical that is bioavailable can exert toxic effects. Therefore, adequate hazard and risk assessment requires sufficient knowledge on chemical bioavailability. Thus, besides use of in vitro tools for metabolism, representative in vitro tools that address in vivo biotransformation of EAS in the whole digestive tract, i.e., including mouth, stomach, and intestine, also are needed (Oomen et al., 2003).

Digestion models can be better understood in three parts; one concerned with the upper digestive tract, the second for small intestinal tract absorption, and the third incorporating metabo- lism. The large intestinal tract generally is not taken into account, as the small intestine is the primary site for food digestion and absorption.

- The first part of the digestive tract, i.e., mouth, stomach and duodenum (first part of the small intestine) can be represented by an in vitro digestion model. The model described by Oomen et al. (2003) includes a standard meal to which to a chemical of interest is added. Digestion is simulated by adding in sequential order: saliva; gastric juice; duodenal juice; bile and a bicarbonate solution. Among others, this model has been used to assess the bioaccessibility of mycotoxins from food (Versantvoort et al., 2005). The TNO gastro-intestinal tract model (TIM), a dynamic computer-controlled in vitro system that mimics the human physiological conditions in the stomach and small intestine, is more complex. It contains four compartments and has been used to study the absorption of heterocyclic aromatic amines and the degradation of gluten (Krul et al., 2000; Mitea et al., 2008).

- At the point of the small intestine, absorption of substances and water become the main issue for bioavailability, although occurrence of metabolism in the intestine often has been underestimated (Van der Kerkhof et al., 2006) and is bacterial in origin, in addition to endogenous enzymes. For example, the isoflavone daidzein can be metabolized to the more selectively potent ligand, S-(-)equol enantiomer, for ER $\beta$, by gut bacteria in rat models and some adult humans (Setchell and Clerici, 2010). Absorption is most often modelled in vitro by using human intestinal Caco-2 cells to study intestinal transport. Trans-well inserts covered with a monolayer of Caco- 2 cells exposed at the apical side, and both transport and metabolism, can be investigated by analyzing the apical or basolateral medium (Versantvoort et al., 2005; Verwei et al., 2005).

- Intestinal metabolism and first pass gut extraction may be responsible for about $10-60 \%$ of the metabolism of a chemical and may increase systemic availability through repeated cycles of absorption and efflux. A selected example is reported in healthy volunteers for an oral dose of cyclosporine from a Sandimmune ${ }^{\circledR}$ formulation. On average, about $86 \%$ was absorbed, and just over half of the oral dose was metabolized in the gut wall, while only $8 \%$ was lost to hepatic first-pass metabolism, resulting in a bioavailability of $27 \%$ (Benet and Cummins, 2001). The authors suggest that CYP3A and $\mathrm{P}$-glycoprotein may play complimentary roles in drug absorption, distribution, metabolism, and excretion by biotransformation and counter transport, especially in the villi of the small intestine, as also indicated in the liver drug metabolism literature. Other drug examples include terbutaline and isoproterenol: both have been shown to be mainly metabolized in the gut (Benet and Cummins, 2001; Davies et al., 1974; Shen et al., 1997; Tegnér et al., 1984).

- The most important isoforms of the cytochrome P450 family in the intestine are CYP2C9, CYP2C19, CYP2D6, and CYP3A4 and their expression decreases from the duodenum and jejunum to the ileum and colon (Coecke et al., 2006). Phase II metabolism in the intestine may even be comparable to that in liver, although the UDP-glucuronosyltransferases 
(UGTs) UGT1A7, UGT1A8, and UGT1A10 are intestine specific and are not expressed in the liver (Gregory et al., 2004). Use of intestine microsomes may give a strong underestimation of the in vivo intestinal metabolism, while use of intestine slices has been shown to be a relevant model. For instance, the metabolism of testosterone in human intestine slices was shown to be equal to that of liver, yielding androstenedione via conversions by CYP2C9, CYP2C19, and 17 $\beta$-hydroxysteroid dehydrogenase (Van der Kerkhof et al., 2006). On the other hand, the metabolic capacity of Caco-2 cells is known to be rather limited (mainly CYP3A4).

- Both the metabolism and the transport in the intestine can be studied by use of Ussing chambers (Van der Kerkhof et al., 2006). However, this technique is rather complex and labor intensive.

Therefore, medium-term goals emanate from these considerations, such as the inclusion of Caco-2, intestine microsomal, or slice assays in combination with EAS assays separately or in testing batteries.

\section{Proposed projects to foster the integration of metabolism considerations into current EAS/ED screening and testing}

The following proposed projects are built upon the recommendations in the metabolism DRP (Jacobs et al., 2008; OECD, 2008) and are designed to facilitate the addition of reliable and ultimately validated methods for evaluating metabolism into the current framework for the screening and testing of EAS. Accurate hazard assessment using in vitro models is hampered not only by insufficient knowledge of metabolism but also by a lack of information on bioavailability. As described above, the current paper also briefly addresses in vitro digestion and bioavailability models. Organized to address short, medium, and long-term goals, these recommended projects target issues associated with the evaluation of chemical digestion, metabolism, and bioavailability in assays used for screening and prioritization of chemicals. Potential issues within these projects and case study examples are given in the following sections. Although the projects will focus initially on in vitro assays designed for the estrogen, androgen, thyroid, and steroidogenesis (E, A, T, S) modalities, the methods and approaches described here could be applied to assays addressing other hormone systems/pathways as they are developed.

\subsection{Short term goals}

The short-term goals are, first, to validate in vitro assays for EAS that incorporate metabolizing systems, and, second, to test the inherent metabolic capability of cell lines used in the EAS assays. Traditional methods that have been used for many years to incorporate metabolism into genotoxicity testing can be used. Uptake in the field of endocrine disruption has been slow, but some groups are now using these methods successfully in mammalian and non-mammalian-based assay systems (Li et al., 2011; Morohoshi et al., 2005; Rijk et al., 2008; Schmieder et al., 2004; Taxvig et al., 2011).
The complexity of the process of integrating metabolic assessment into validated in vitro EAS assays may be simplified by focusing on targeted questions, which first should address the characterization of metabolic capability of in vitro systems and then address how to incorporate (additional) metabolism into in vitro systems as needed.

While a comprehensive background is provided in the metabolism DRP (OECD 2008) and Jacobs et al. (2008) and does not need to be duplicated in this paper, applied examples of project approaches follow below.

\subsubsection{Projects}

The following list provides the projects that need to be undertaken to address the short term recommendations:

1.A starting point is to establish a reference set of chemicals for testing in vitro metabolism systems in EAS assays. This will facilitate the harmonization of the validation of metabolizing systems to be incorporated into endocrine activity assays.

2. Validation of tests incorporating liver $\mathrm{S} 9$ fraction into in vitro assays designed to detect endocrine activity.

3. The inherent metabolic capability of the cell lines selected for validation studies in Project 2 should be tested at the same time.

4. Continue to compile and publish the knowledge on metabolic capacity of cell lines used in all OECD TGs as well as those being proposed in new OECD TGs.

Validation studies for Projects 2 and 3 could be initiated immediately.

\subsubsection{Key considerations for research approaches for short term projects}

An initial step that is needed to support the accomplishment of the short term goals (as well as the medium and long-term goals that follow) is the compilation of a set of reference chemicals for assessing the metabolic capacity of EAS assays that can become a part of accepted international validation procedures. This will allow inter- laboratory comparisons of the EAS assays with and without metabolizing systems. The list should include a panel of EAS and steroid hormones known to be modulated by metabolism, as well as appropriate non-metabolized EAS and steroid hormones. The potencies of the parent chemical and/or metabolites for the relevant EAS assays should be documented for each chemical, and both positive and negative controls (min 25\% negative) should be included. Chemicals that might be included in a reference panel when investigating metabolism of EAS in these assays could be based upon in vitro validation studies included in the OECD TG work program (e.g., $17 \beta$ estradiol, methoxychlor, testosterone, and di(2-ethylhexyl) phthalate (DEHP)). It also would be relevant to include chemicals that address specific enzymes or metabolic systems (e.g., specific P450's and phase II enzymes) that may be unrelated to EAS/EDs.

To address assay variability versus normal biological metabolic variability, cut-off values for the in vitro assay are set such that differences are not considered "positive" unless they exceed the normal range of biological variability. When the variability among in vitro assays is greater than the normal range of bio- 
logical variability, a potential solution is a concordance analysis with assays for the same endpoints, both in vitro and then in vivo where data already exists, or for subsequent in vivo screening and test prioritization purposes (e.g., ER binding assays first with estrogen proliferation assays and ER reporter gene assays, and then with uterotrophic assay) to discern whether any respond with sufficient precision to allow biologically significant changes to be identified and thus inform the AOP.

A standard may therefore be set for in vitro metabolic assays based on an understanding of the normal range of biological metabolic variability. The utility of an assay - and therefore the strength of evidence attributed to its results - might be characterized by its ability to detect differences sufficiently small to identify biologically significant changes.

For example, Kuuranne et al. (2008) successfully used human S9 liver mixes on selective androgen receptor modulators (SARMs) to predict the in vivo marker metabolites. Similarly, bovine $\mathrm{S} 9$ mixes have been used with SARMs and showed that the metabolites formed also were found in vivo (De Rijke et al., in press). Furthermore, these two examples using human and bovine (from food industry production) liver sources demonstrate effective replacement of S9 fraction from experimental animal sources.

With respect to i) relevant concentration levels of test chemicals to be tested, both range finding and subsequent dose response curves are given in the OECD TGs 455, 456, 457; and ii) the concentrations of S9, and particularly, the required speciesspecific concentrations to add, the reader is referred to the original experimental papers cited in OECD (2008), Jacobs et al. (2008), and herein. Use of additional models, such as those for digestion or ADME (bioavailability), may be useful for resolving and refining $\mathrm{S} 9$ concentrations (see also Section 2.2). The in vitro metabolism data can inform metabolic model parameters of PBTK modeling to assist in the accurate representation of in vivo metabolic processes, both qualitatively and quantitatively. However, the development of more case study research is needed for the further development of proofs of principle for incorporating PBPK modeling (Punt et al., 2011).

Regarding the selection of EAS assays for inclusion of S9 fractions (Project 2), some suggestions are listed in Section 2.2. In order to reduce variability when testing S9 fractions, it would be better to test them in combination with EAS assays that have already undergone successful validation/transferability testing. Although many assay systems would be suitable, in practice, assay variability may be greater than metabolic variability. Thus successful validation is more likely if guideline cell systems are used. It is also likely to be faster.

If validation with the inclusion of the $\mathrm{S} 9$ fraction is successful for the ER transcriptional activation assays with well characterized endogenous metabolic capacities (Project 3), then the system could be expanded rapidly to other receptor assays, e.g., androgen receptor (AR), thyroid receptor (TR), aryl hydrocarbon receptor (AhR), progesterone receptor (PR), and peroxisome proliferator activated receptors (PPARs) (OECD, 2008), and as identified in the OECD Detailed Review Paper: State of the Science on Novel In vitro and In vivo Screening and Testing Methods and Endpoints for Evaluating Endocrine
Disruptors OECD (2012d). A performance-based test guideline (PBTG) approach, as recently developed for the ER STTA assays in TG 455 (OECD, 2012b) for the metabolism element, could possibly be followed.

With respect to the thyroid receptor (TR) and the T-screen (T-Screen; thyroid induced proliferation of rat GH3 pituitary adenoma cells, Gutleb et al., 2005), the T-screen has a major drawback, as most thyroid EAS/EDs do not interact with the receptor but interfere with the transport of the hormones triiodothyronine (T3) and thyroxine (T4) in blood or the T3 and T4 synthesis. Regarding the latter, a cell line or another in vitro cell system that is able to produce T3 and T4 is urgently needed and regarded as a top priority. Alternatively, thyroid peroxidase (TPO) enzyme assays can be set up and combined with S9.

The choice of species and use of enzyme inducers in relation to S9 production, therefore, needs careful consideration. If a substance is suspected of being a potential ED on the basis of in vitro tests using enzymes and molecular targets of human origin, and the substance is going to be finally tested in vivo, it is advised to first confirm metabolic activity in vitro, with materials obtained from the animal species and strain that will be used for the in vivo test.

One way forward may be to try both rat and human liver S9 in pre-validation studies. The reason for conducting studies in these two species would be to assess qualitative and quantitative species differences in metabolism as well as variability between human S9 sources. Historically, the quality of human liver subcellular fractions has not always been good, but this may be improving. Assessment of batch-to-batch variability also is needed. If human S9 is not found to be a reliable source of metabolizing enzymes, then the replacement of rat S9 would be a future medium to long-term goal regarding the reduction of animal use (see Section 3.3.1: long term recommendations).

\section{The choice of species providing $S 9$}

- Rat liver S9 is most commonly used as a source of metabolizing enzymes. It has the advantage of being generally easy to obtain and of reliable quality. It should be obtained from rats induced with phenobarbitone and 3-methylcholanthrene, not Arochlor polychlorinated biphenyl mixes (re: Stockholm Persistent Organic Pollutants Convention). Pre-treatment of the rats with these enzyme inducers increases the activity of the xenobiotic metabolizing enzymes. For routine screening purposes this would be a good choice. Positive in vitro endocrine assays are likely to be followed up by in vivo assays from the OECD conceptual framework (OECD, 2012a). Since many of the in vivo assays use the rat as the animal model, it would make sense to have consistency of metabolism between these assays by using the same species.

- On the other hand, the choice of species will be influenced by the overall objectives for the research and/or hazard/risk assessment. For example, from an environmental perspective, if a substance is suspected to have effects on a fish species, then the use of a fish liver S9 system may be most appropriate. Recent sources of fish S9 are described in Han et al. (2009) and Gomez et al. (2011). Trout S9 fractions have been used as metabolic "activating" systems in different assays such as 
Ames tests. De Flora et al. (1982) used both rat and trout S9 fractions. Efforts to standardize trout S9 protocols are described in Johanning et al. (2012).

- When extrapolating results for human health hazard assessment, it may be more appropriate to use human liver S9. In fact, most of the in vitro assays used for EAS/ED testing use human receptors and human cell lines.

- Another consideration may be the use of S9 fractions isolated from porcine or bovine tissues. This could provide an alternative when using animals killed for food purposes. However, the current use of porcine and bovine tissue for regulatory purposes is not widespread.

\section{Potential drawbacks for use of 59}

- While S9 is very useful, it is important to address a potential drawback for its routine use (see Tab. 1), i.e., that the S9 liver fraction needs cofactors, and it may not be known what cofactor is needed for the chemical under investigation. Traditionally, NADPH is used as the cofactor for mixed function oxidase activity (Chalbot and Morfin, 2005), but NAD ${ }^{+}$ facilitates reduction of substances, e.g., by dehydrogenases and oxidoreductases. As an example, the metabolism of the prohormone dehydroepiandrosterone (DHEA) using bovine liver S9 has been shown to be strongly cofactor dependent, allowing conversion to $17 \beta$-testosterone via 4 -androstenedione when using $\mathrm{NAD}^{+}$, or via 5-androstenediol when using the cofactor NADPH (Rijk et al., 2008).

- Binary S9 cofactor systems may include cofactor combinations. Examples of these include: 1. Rat liver microsomes used with a recombinant cell bioassay (RCBA) expressing the human ER $\alpha$ linked to a reporter gene for the detection of EAS in food. Methoxychlor and mestranol are shown as model compounds (Coldham et al., 2002). 2. A two-step approach whereby the first step (Phase I) used a mixture of human liver microsomal and S9 fractions in a phosphate buffer with NADPH, and for the second step (Phase II) either UDPGA or PAPS were added for glucuronidation or sulfation, respectively. In this example, the application was for the bioactivation and biodegradation of selective AR modulators (Kuuranne et al., 2008).

\section{Tab. 1: Technical considerations for use of $\mathrm{S} 9$ and possible solutions}

\begin{tabular}{|c|c|}
\hline Potential technical difficulty & Potential solution \\
\hline $\begin{array}{l}\text { The method of S9 incubation } \\
\text { needs to be considered }\end{array}$ & $\begin{array}{l}\text { S9 may be co-incubated with the cells and chemical (Li et al., 2011) or a chemical may be } \\
\text { pre-incubated with S9 and then the extract applied to the assay (Taxvig et al., 2011). In general, } \\
\text { co-incubation is a time-saving approach but may lead to cytotoxicity in the assay system. }\end{array}$ \\
\hline $\begin{array}{l}\text { Cytotoxicity of S9 to cell-based } \\
\text { assays is tested }\end{array}$ & $\begin{array}{l}\text { This will vary according to the assay, but a sensitive method of determining cytotoxicity } \\
\text { should be used routinely for all cell-based in vitro assays. A potential solution would be to } \\
\text { perform the metabolism and EAS assays in series (i.e., to separate them physically). }\end{array}$ \\
\hline Monitoring of variables & $\begin{array}{l}\text { Variables such as incubation time, plastic ware, culture medium, edge effects, etc., may need } \\
\text { monitoring, but close attention to the standard operating protocols (SOPs) and performance } \\
\text { standards, such as those contained in OECD Performance Based Test Guidelines for users and } \\
\text { OECD Performance Standards for test developers (e.g., the Performance Based Test Guide- } \\
\text { line no. } 455 \text { for the Stably Transfected Transcriptional Activation Assay for the Detection of } \\
\text { Estrogen Receptor Agonists and Antagonists (PBTG ER STTA), (OECD, 2012b) together with } \\
\text { guidance from groups routinely running these assays can be obtained. Furthermore, microbial } \\
\text { contamination needs to be avoided. }\end{array}$ \\
\hline Protein binding & $\begin{array}{l}\text { This should be evaluated, as some chemicals bind extensively to proteins and can potentially } \\
\text { affect chemical availability (e.g., in the case of furazolidone, Hoogenboom et al., 2002; for EAS in } \\
\text { Heringa et al., 2004). }\end{array}$ \\
\hline Physico-chemical properties & $\begin{array}{l}\text { Properties such as volatility, solubility, absorption to glass or plastic ware should be assessed } \\
\text { to ensure accurate dosimetry of the parent compound and metabolites (e.g., the possible } \\
\text { absorption of dioxins or other chemicals to plastic ware). The protocol needs to include chemical } \\
\text { analysis to determine the proportion of parent compound that has been metabolized as well } \\
\text { as to identify metabolites. Preferably, analytical methods could be recommended to laboratories. } \\
\text { For instance, with respect to androgenic activity, the metabolic quality of liver S9 mixes or liver } \\
\text { slices often is checked with an androgen like testosterone and DHEA, using ultra-performance } \\
\text { liquid chromatography (UPLC) and time-of-flight mass spectrometry (TOFMS) to confirm } \\
\text { the formation and identity of metabolites like 4-androstene-3,17-dione and 5-androstene-3,17-diol } \\
\text { (Rijk et al., 2008). }\end{array}$ \\
\hline $\begin{array}{l}\text { Batch-to-batch quality control of } \\
\text { serum, medium, and supplements } \\
\text { used for cell cultivation in cell- } \\
\text { based EAS assays }\end{array}$ & $\begin{array}{l}\text { This may result in false positives due to protein binding problems, for example, if batches of } \\
\text { serum are not well controlled. All media should be tightly controlled as far as possible. }\end{array}$ \\
\hline
\end{tabular}




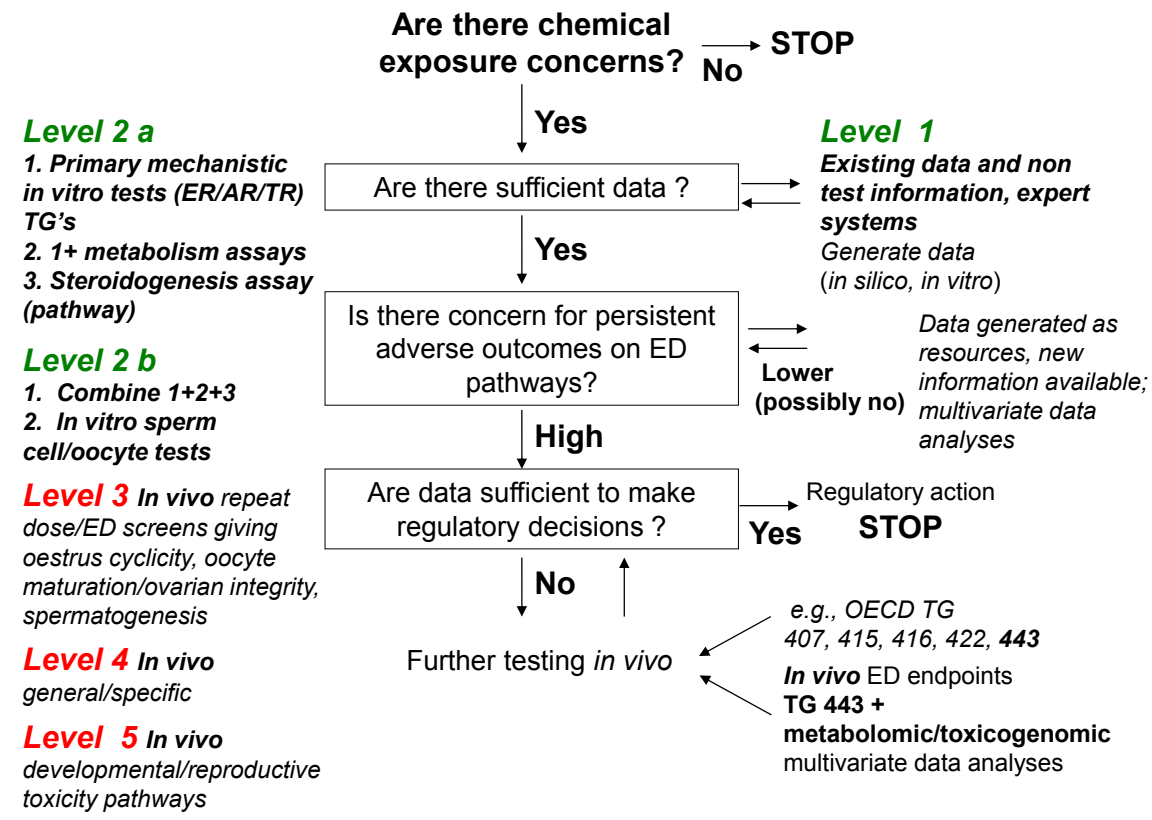

Fig. 1: Scheme showing the levels for the potential for incorporation of metabolism and "genomic" tools to identify metabolism in an iterative fashion into the updated OECD EAS Conceptual Framework

- The use of liver slices provides a metabolizing system that may more closely reflect the in vivo situation with all the relevant cofactors present. In addition, liver slices combine Phase I and II metabolism (Rijk et al., 2012). However, a potential drawback when using slices is their capacity (i.e., many slices are needed), and that reproducibility may be reduced, particularly as one cannot use homogenized mixes from a number of different animals. Efforts have been made to reduce this by way of cryopreservation of large batches of slices (e.g., De Graaf et al., 2007). Use of precision cut liver slices, with their endogenous metabolism and cofactors has proved to be a reproducible system for measurement of ER-mediated gene activation in fish (Schmieder et al., 2004). Other alternatives include the use of liver microsomes (Volotinen et al., 2007), supersomes (Roy et al., 1999), hepatocytes in co-culture with endothelial cells (Harimoto et al., 2002; Pagliara et al., 2003; Weiss et al., 2002) and liver cell lines commonly used in drug metabolism studies, such as HepG2 (Westerink and Schoonen, 2007), although these are not always very easy to handle, particularly for medium to high throughput. The advantages and disadvantages of these different liver models were previously reviewed in relation to endocrine active substances (Jacobs et al., 2008; OECD, 2008) and drug metabolism (Plant, 2004).

Once a metabolizing system has been validated, it then can be used in combination with the in vitro tests within Level 2 of the OECD conceptual framework (Fig. 1). A next step could be to formally document existing knowledge of the metabolic capability and metabolomic data for validated EAS in vitro assays as well as for any assays being proposed for validation, including those being indicated in the new endocrine endpoints DRP No. 178 (OECD, 2012d). This activity could be undertaken by the VMG-NA, perhaps taking the form of the development of a guidance document for best practices for documenting metabolic capability of cell lines, as well as quality assurance (QA) methods to demonstrate retention of metabolic capability over time.

\subsubsection{Case study}

Use of a metabolically competent in vitro assay system within the context of an adverse outcome pathway

An approach to incorporating metabolism into in vitro assays is illustrated through the development of an ER Binding Expert System for prioritizing chemicals for the US EPA's EDSP Tier I Screening Battery (US EPA, 2009; US EPA FIFRA SAP, 2009a,b). An ER-mediated reproductive impairment AOP pathway in fish is the foundation of the approach. While for fish a major point of entry of EAS exposure is via the gill, it is well known that fish also are exposed to EAS via their diet, (see for example, Jacobs et al., 2002; Carlson and Hites, 2005), and thus phase II metabolism via the liver is a relevant metabolic pathway for fish.

Two in vitro assays are used in combination to detect weak, but significant, ER activity of chemicals that are not structural- 
ly related to potent ER agonists or antagonists. The molecular initiating event of the AOP is binding to the ER. Therefore, a cell-free ER binding assay is used as the primary assay to determine ability of a parent chemical to interact with the receptor. For chemicals demonstrating binding affinity, a second assay, a metabolically competent rainbow trout liver slice assay, is used to verify that ER binding translates to gene activation (by measuring vitellogenin (VTG) mRNA) in the presence of xenobiotic metabolism (Schmieder et al., 2004). If a chemical that was shown to bind ER in the cell-free assay does not induce VTG mRNA in the liver slice assay, additional slice assays are run to determine if the chemical can inhibit VTG formation when administered in combination with estradiol (e.g., antagonist activity).

The use of the two assays in combination has allowed the higher throughput ER binding assay to be used to test more chemicals, and the lower throughput assay to be used to verify if a chemical has activity at a more complex level of biological organization along the AOP. By testing a smaller subset of chemicals using in vivo assays, the AOP linkage can be further confirmed, particularly the ability of a chemical that is a receptor binder (in this case, ER) to produce adverse effects. The two in vitro assays can be used to prioritize, within a large chemical inventory, which chemicals are most likely to interact with ER, to refine targeted in vivo testing. Chemicals within the inventory are organized into chemicals classes, then testing within the class is done on a few chemicals to (e.g., low, medium, high $\log \mathrm{K}_{\mathrm{ow}}$ ) to determine the likely limits of ER modulation of all within the class. In addition, the structural attributes associated with ER binding, and ultimately with activity or inactivity, can be determined. Reviews conducted by both the OECD (2009) and the US EPA (US EPA FIFRA SAP, 2013) concluded that the model was relevant for both human and environmental chemical screening purposes for EAS activity, particularly for prioritization purposes.

Using analytical chemistry techniques, chemical mass balances and the uptake and elimination dynamics of the chemicals within the metabolically competent liver slices can be monitored (Schmieder et al., 2004). Moreover, if a chemical is negative for ER binding, but with a high potential for metabolic activation based on its chemical structure, the system also can be used to detect chemicals that are metabolized to an ER-active metabolite. The ER binding assay then can be used to directly confirm the binding of the metabolite, where its structure is known and a chemical standard is available. In addition, the liver slice assay also can be used to verify that chemical ER agonism seen in other TA assays is sufficient to produce VTG induction in a system where oxidative and conjugative metabolism might convert and eliminate the parent chemical.

\subsection{Medium term goals}

The medium term goals are first to address the overall strategy for the incorporation and integration of in vitro metabolism tools into testing batteries. The number of in vitro metabolism tools also needs to be extended in order to cover new EAS assays, including those discussed in Section 2.3 covering absorption by the gastrointestinal tract. Second, relevant information should be collected from the in vitro assays and the emerging in vivo information from the use of the Extended One Generation Reproductive Toxicity Study (OECD TG 443, OECD, 2011b) and the other higher level tests at Levels 4 and 5 in the OECD revised conceptual framework (OECD, 2012a) (see Fig. 1). These data should be integrated into new assessment paradigms. The proposed time for this correlation of in vitro and in vivo results would be three to five years.

\subsubsection{Projects}

1. Inclusion of predictive models and in vitro assessments of metabolism along with assays for EAS activity

This could be implemented in an organized system of test batteries also within the next 3-5 years. These new metabolism assessment tools could be added to the various levels of the OECD Conceptual Framework, (see, for example, suggestions for Level 2 in the scheme shown in Figure 1, where for ease of understanding in vitro test complexity and test combinations are described under $2 \mathrm{a}$ and $2 \mathrm{~b}$ ).

In this scheme, the first step would identify any chemical exposure concerns and evaluate existing data and non-test information to determine whether further testing is necessary. Level 2 tests then would be used for screening purposes and prioritization of a chemical for further (in vivo) testing. A tiered approach could be taken where a series of Level $2 \mathrm{a}(1)$ in vitro assays would be conducted to provide mechanistic data that reflect a number of molecular initiating events (MIE), such as those associated with steroid receptor (e.g., ER, AR, TR) activation. These assays then could be conducted together with a metabolizing system (Level $2 \mathrm{a}(2)$ ). Finally, additional pathway tests, such as the steroidogenesis (OECD TG 456, OECD, 2011a) could be conducted (Level 2a(3)). Level $2 \mathrm{~b}$, would address the combination and interpretation of the data generated in Level $2 \mathrm{a}(1+2+3)$, together with subsequent pathway information that could be informed by additional in vitro tests (e.g., in vitro oocyte and sperm cell tests).

2. Collation and integration of information from in vitro assays and in vivo assays at higher levels of the OECD conceptual framework into new assessment tools

The information generated in this way could enable the subsequent in vivo priority testing of any chemicals that exhibit a high probability of causing persistent adverse outcomes on endocrine pathways. Levels 3, 4, and 5 address in vivo testing with increasing complexity and also animal use/test duration. Data generated at Levels 3 or 4 may be sufficient to make a regulatory decision, so it may not be necessary to conduct further in vivo testing in Level 5, e.g., TGs 416 (OECD, 2001), TG 422 (OECD, 1996), TG 443 (OECD, 2011b). Where additional in vivo information is generated, the metabolism and genomic tools can assist in the further metabolic development of the in vitro tests at Level 2.

Criteria for interpretation of the results of combined in silico and in vitro testing would need to be developed. Uses of principle component, multivariate, and cluster analyses are useful for study designs that can optimize test batteries addressing metabolism. For example, meta-analyses of gene expression 
of micro array data sets, such as that used for $17 \beta$ estradiol (E2) in MCF-7 cells (Ochsner et al., 2009), combined with a characterization of the metabolic capacity of MCF-7 cells, and the integration of such genome experiments (Lachmann et al., 2010) for other cell lines and reference chemicals, could aid the iterative improvement of transcription factor regulation data and metabolism inferences for the in vitro TGs in Level 2.

A freely available reference collection of gene expression profiles from cultured human MCF-7 cells, the "Connectivity Map" (http://www.broadinstitute.org/cmap/) contains data for over 1500 substances, and includes pattern-matching software for data mining. It was demonstrated that the map can identify substances sharing a mechanism of action in MCF-7 cells (Lamb et al., 2006). Profiling new compounds and subsequent pattern matching can assist in the prioritization of chemicals for further hazard testing.

\section{Extension of the battery of in vitro assays for EAS} incorporated into OECD test guidelines

The battery should be extended by inclusion of other assays as rapidly as they can be rigorously validated for other modes of action, or assays with other measurements that reflect MIEs that complement the receptor assay. Additional relevant assays include the MCF-7 based cell proliferation assay for ER modulators (e.g., Bitsch et al., 2002; Gutendorf and Westendorf, 2001; Rasmussen and Nielsen, 2002; Rasmussen et al., 2003; Soto et al., 1995; Swart and Pool, 2009; Villalobos et al., 1995; Wagner et al., 2008; Wagner and Oehlmann, 2011; Wang et al., 2012).

4. Inclusion of assays for determination of absorption and bioavailability

These should also be validated or included as standardized tests within a battery. The Caco- 2 model seems to be the most practical model to study transport (bioavailability), while intestine slices are a practical model to study intestinal metabolism. Thus, additional efforts are suggested to increase the metabolic capacity of the Caco-2 model to make it suitable to study transport and metabolism at the same time.

5.Characterization of predictive value for adverse endocrine-mediated effects

In vitro methods in general will be viewed as stronger and will be more readily accepted if their positive and negative evidence predictive value for adverse endocrine-mediated effects is characterized. In this respect Akahori et al. (2005) and Wang et al. (2012), for example, demonstrate good concordance for in vitro estrogen pathway related assays (i.e., ER binding, and MCF-7 proliferation assays) with the in vivo uterotrophic assay for example. Wang et al. (2012), report that the MCF-7/BOS cell DNA proliferation assay showed a very good correlation with the in vivo uterotrophic assay $\left(\mathrm{R}^{2}=0.87\right)$, greater than that for proliferation assays based on other human cell lines.

\subsubsection{Key considerations for research approaches for medium term projects}

To be most effective for international acceptance and use of organized systems of test batteries, key considerations will need to be addressed to reduce potential bottlenecks in test develop- ment, as seen, for example, in the conflicting recommendations of different national and supranational authorities. In Europe, the European Commission Directorate General (DG) Enterprise may encourage patenting of test systems and test batteries. However, this is not recommended for TG development since monopolies are not permitted in either Europe or the OECD. Thus, while patented and/or proprietary assays may be quite applicable for use in a proposed test battery, their incorporation as part of the OECD Conceptual Framework may be hampered. Approaches that will further foster international consensus on how to move forward on these issues would greatly improve progress.

Analysis of the concordance between specific endpoints from in vivo and in vitro EAS assays could be used to refine and improve the in vitro tests in an iterative fashion to better predict the in vivo endpoints and thus reduce animal usage.

\section{Other considerations and recommendations}

- Any one battery of assays will not be appropriate for the universe of substances to be tested, but similar optimum designs are possible with knowledge of chemical categories and specific AOPs of interest.

- The continued iterative development of QSAR and molecular modeling docking studies for the analysis of potential EAS, to assess the metabolic capacity of the assay system, and to compare the results obtained in vitro with those generated by the in silico pre-screen can continue to document the reliability of in vitro metabolizing systems in batteries of tests. Information generated from the new in vitro test can be utilized to refine the in silico molecular models and refine and update the QSARs.

- An agreed approach for using metabolism information along with EAS assay information could be developed for screening and prioritization of chemicals. This should address the use of data from EAS in vitro tests and from metabolism tests.

- Tests for EAS should be identified that are of most scientific promise or that address endpoints of greatest regulatory need for prioritized development. Preference should be for those tests that may be combined most easily with a simultaneous assessment of metabolism of the substance under study (OECD, 2012a).

- Initiate new studies that would incorporate metabolic capacity into existing functional tests, particularly in vitro test guidelines or that would incorporate endocrine molecular targets into existing cell lines with metabolic capacity.

- Mammalian cell lines have long been engineered to express one or more metabolic enzymes, including various Phase I and Phase II enzymes (Bull et al., 2001; Coecke et al., 2002; Jacobs et al., 2008; OECD, 2008; Wiebel et al., 1997) some of which are now commercially available. Such multiple gene expressing cell lines could then be utilized to investigate the metabolic activation and detoxification of potential EAS in vitro.

- The feasibility of "omics" applications for measuring metabolic capacity for regulatory use should be reviewed.

- To date, most attention has been focused on the estrogen, androgen, thyroid hormone systems and steroidogenesis as mode of 
actions for EDS. However, other hormonal and ED pathways are now envisaged that include the hypothalamic-pituitary-gonadal (HPG) and somatotrophic axes, as well as mechanisms related to reproduction, development, and lipid homeostasis, such as the peroxisome proliferator activated receptors (PPARs) and retinoid signaling (RXR) pathways, the glucocorticoid receptor and vitamin $\mathrm{D}$ signaling pathway, and putative epigenetic mechanisms (OECD, 2012d; Greally and Jacobs, 2013).

- Implementation of 3-dimensional (3D) reconstructed tissues and microfluidic devices in order to generate cell based effect assays with improved metabolic capacity, or for metabolite production as a more relevant replacement for enzyme extracts such as S9. 3D reconstructed liver tissue is being developed by several private enterprises and research facilities. These tissues and devices not only allow the study of chemical metabolites in models that are closer to the in vivo tissue structure, they also can be used in combination with other in vitro assays (e.g., receptor binding, transcriptional activation) to provide metabolic capacity. The feasibility of combining these methods should be investigated.

- It is necessary to use all information available on metabolism from other assays (e.g., in vitro tests to detect the interference of chemicals with steroid and thyroid hormone synthesis), together with consultation of the relevant related DRPs (OECD, 2006, 2010, 2012a,d) for an adequate weight of evidence review.

\subsubsection{Case Study}

\section{Exploration of the feasibility of a battery approach}

The EU $5^{\text {th }}$ Framework Programme project entitled "Dysregulation of endogenous steroid metabolism potentially alters neuronal and reproductive system development: effects of environmental plasticisers (QLRT-02637)" (ENDOMET), provides a case study for the use of a battery approach. The selected chemicals represented different classes, i.e., phthalates, alkyl phenols, and adipate classes. Their effects were measured on parameters from five different tests selected from 23 in vitro tests using cluster analysis to identify "bottleneck" potential AOPs for steroid metabolism and function. The analyses identified four different pathways for which the in vitro test panel of the five selected assays could potentially be used as an indicator for their classification as a potential human endocrine disruptor. For this example, critical pathways were shown to include estrogen synthesis and sulfonation, synthesis of sulphate/PAPS (3'-phosphoadenosine-5' -phosphosulphate), and thyroid hormone regulation so that the activity profiles of some Phase I and Phase II reactions can be used as biomarkers for detection of compounds with ED potential.

The five tests identified were: sulfite oxidase (SOX) activity; sulfotransferase (SULT)1A1 activity; PAPS synthetase (PAPSS) activity; aromatase; and the T-screen assay. These five tests utilize human or rat cell lines and are considered to be relevant for humans. The initial 23 tests included the thyroid as a target, neuronal cell lines and also included tests for steroid synthesis and metabolism, as well as the classical nuclear receptors (NRs). While this group of tests still needs further optimiza- tion and more substance testing (e.g., so far they have only been tested for a range of phthalates, alkyl phenols, an adipate, and miscellaneous EDs: Sung et al., 2012; Waring et al., 2012), this project demonstrates how cluster and multivariate analyses can be used for designing specific test batteries for different chemical classes. Critical metabolic pathways and AOPs of toxicological significance can also be identified.

\subsection{Long term goals}

The long-term goals are intended to build a foundation for the effective use of in silico and in vitro approaches to metabolism. Not only for the screening/prioritization of EAS but also for future use in chemical risk assessment and management. It is recognized that the complexity of in vivo metabolism presents tremendous challenges for the development of predictive models suitable for the extrapolation of data from in silico/in vitro approaches to that which (can) occur in vivo. Thus, the following projects are intended to foster an international harmonization of databases, delineation of metabolic pathways, and development of predictive tools that will provide a fundamental understanding of the processes by which metabolism occurs and begin to increase the predictive accuracy of in silico and in vitro methods.

\subsubsection{Projects}

Development of systematic (and standardized or validated) approaches for improving and utilizing in vitro metabolizing systems, chemical metabolic databases, and established (or newly discovered) AOPs to more accurately link chemical exposure (i.e., parent and/or metabolites) with initial molecular events, intermediate steps, and adverse outcomes in vivo.

\subsubsection{Key considerations for research approaches for long term projects}

Information on metabolites formed from xenobiotic chemicals in different species and experimental systems will increase the predictive accuracy of in silico and in vitro methods. For example, in silico systems that report or predict metabolites formed from a parent chemical can serve as input to in silico models that predict the ability of any chemical structure, whether as an administered parent compound, or a metabolite present in sufficient quantity, to interact with a biological target (molecular initiating event) and start a series of events leading to an adverse outcome (Fig. 2). Additionally, as described above, activities measured in vitro using systems that do not include metabolism, combined with results derived from systems with metabolism, can be compared to gain an understanding of whether the parent chemical form, or a metabolite, or both, are contributing to measured assay activities.

Knowing what metabolites are formed from a parent chemical allows each metabolite structure, in turn, to be administered as the exposure chemical in an in vitro system with no metabolic capability. If the parent form is inactive in the assay, but any one of the metabolites is found active, then the potential for an administered parent chemical to result in endocrine activity in a metabolically competent system can be assessed. This is ex- 


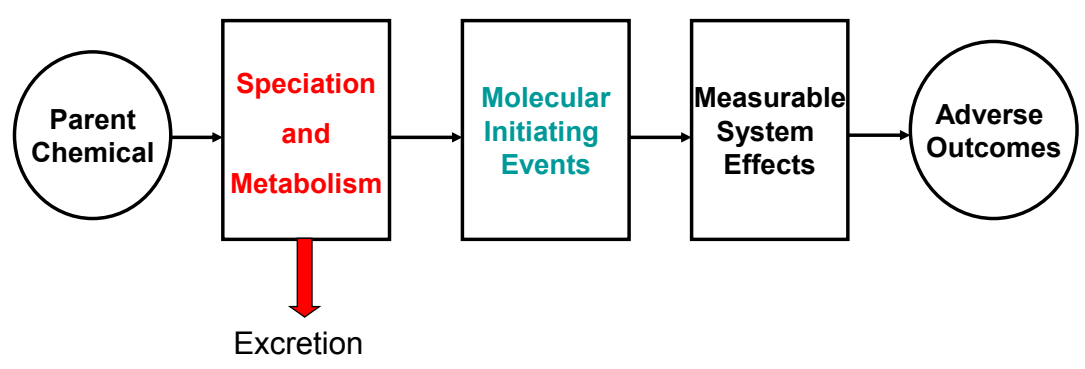

Fig. 2: Role of metabolism in changing an administered chemical form, resulting in a chemical that can initiate an adverse outcome pathway, or resulting in inactive metabolites that are excreted

tremely important for in silico systems and QSAR approaches, i.e., that the in vitro and in vivo observed activities and effects are addressed to the correct chemical structure.

Toward this goal, the delineation of metabolic pathways is necessary and, in fact, is fairly well developed in some areas. For example, the KEGG pathway database ${ }^{4}$ contains numerous endogenous metabolism pathways, including several xenobiotic biotransformation pathways for specific compounds showing metabolites, enzymes likely involved in the biotransformations, and endogenous pathways in which those enzymes are found. The US EPA's MetaPath tool is a database of xenobiotic metabolism pathways being developed by the EPA's Office of Research and Development in collaboration with the Office of Pesticide Programs, with growing international support through an OECD MetaPath Users Group (Kolanczyk et al., 2012). MetaPath is designed to store and analyze summary information on pesticide metabolites found in several species (rodents, livestock, plants), residues of concern, and environmental degradates. The information is obtained from expert reviews of registrant-submitted studies as found in US and $\mathrm{Ca}$ nadian Data Evaluation Records (DERs) ${ }^{5}$, European Draft Assessment Reports (DARs) and the published Assessment Reports. A public version including a larger database of industrial chemicals' metabolism maps is planned to be released through the OECD QSAR Toolbox. The pesticide chemical maps in the database include metabolites collected from in vivo studies, with additional information on the biological matrix (e.g., urine bile, plasma, feces) in which the metabolite was measured and the quantity of metabolite (usually as a percentage of total radioactive residue for the radiolabelled pesticide used in the exposure). The correspondence of parent chemical and sequential formation of metabolites is provided, as well as the experimental condition under which the metabolites were formed (species, dose level, exposure time, etc.). Information on enzymes involved in the transformations is not available in the database at this time, although the database allows addition of transformation details.

\section{Technical considerations}

- Once several such metabolic/adverse outcome pathways have been articulated, common pathways become evident, as do the relationships between pathways. Many common pathways and pathway linkages have been established already by various systems biology networks (e.g., KEGG, GeneGo, Effectopedia) ${ }^{6}$. Building pathway databases is a continuous and iterative process. However, it is recommended that information eventually be collected within a single common, publically available database (e.g., Effectopedia, MetaPath, OECD QSAR Application Toolbox) that can be used to feed one of the several tools for simulating metabolism (by predicting potential metabolites), including a tissue metabolism simulator (TIMES), (Mekanyan et al., 2004), a knowledgebased expert system for predicting metabolism: METEOR, (Valerio and Long, 2010), and simulators being developed in conjunction with MetaPath ${ }^{7}$. These pathway databases will allow prediction of metabolism and potential adverse outcomes of novel substances and their metabolites. The predictive capacity will continue to increase as information is added and pathways refined. Finally, in order to populate these systems with useful information and refine the Level 2

\footnotetext{
4 http://www.kegg.jp/

5 http://1.usa.gov/15PoDkl

6 http://www.genego.com; http://www.qsari.org/index.php/software/100-effectopedia

7 http://www.epa.gov/pesticides/ppdc/testing/july09/metabolism-tools.pdf
} 
assays (Fig. 1), it is critical that high quality metabolism data be collected on the same chemicals being tested in vitro and in vivo.

- Research is needed to document species and gender differences in metabolism that should be taken into account when interpreting endocrine assay results. Information regarding species differences also should be catalogued and integrated into metabolism pathways to facilitate interspecies and gender extrapolation. In this regard, it is appropriate to have in vitro cell assays with different genetic backgrounds available for comparative chemical specific assessment of different tissues and species responses.

Key considerations: Inclusion of physiologically-based kinetics - A key limitation in the application of in vitro alternatives to systemic endpoints such as reproductive and developmental toxicity and carcinogenicity is that in vitro methods do not provide so-called points of departure, necessary for regulators to set safe exposure limits. PBTK-modelling could contribute to overcoming this limitation by providing a method that allows extrapolation of in vitro concentration-response curves to in vivo dose-response curves. However, while commonly used in drug metabolism research, insufficient examples of proof of principle for chemical risk assessment are available (Punt et al., 2011), although algorithms for predicting partition coefficients into different tissue compartments have been developed for environmental chemicals (e.g., Peyret et al., 2010).

Key considerations: Species differences

- Species variation exists in several basic metabolic processes (e.g., CYP activity) that can affect the biological outcome of chemical exposure (Kawai et al., 2003). For example, wide species differences exist in the ligand binding domains of nu- clear receptors that regulate CYP genes (e.g., the AhR and aryl hydrocarbon receptor nuclear translocator (ARNT), the constitutive androstane receptor (CAR), the pregnane $\mathrm{X}$ receptor (PXR), and the PPARs; Fig. 3), and there is an extensive body of literature that documents this (see, for example, a review by Graham and Lake, 2008). This is in contrast to the hormone receptors for which the variability in vertebrates is far narrower, and why, for example, yeast (Li et al., 2011) and fish ER responses may be considered useful predictors of rodent and human ER responses, c.f. fish liver slice S9 discussed in Section 3.1.3. in relation to the US EPA's ER expert binding system, and analysis conducted by others (Bovee et al., 2008b; Dang et al., 2011; Wilson et al., 2004).

- There are several documented cases of differences in induction of various CYP proteins in response to xenobiotic exposure (e.g., 2,3,7,8 tetra-chloro-p-dioxin (TCDD) induces CYP1A2 in human hepatocytes and CYP1A1 in rats). Species differences should be taken into account when interpreting endocrine assay results. Information regarding species differences also should be catalogued and integrated into metabolism pathways to facilitate interspecies extrapolation.

\section{Key considerations: Gender differences}

- The development and maintenance of sexual characteristics is regulated by hormonal control. The biosynthesis and metabolism of steroid hormones are both carried out by P450 enzymes but in different tissues and by different P450 isoforms (Lewis, 1996). Testosterone metabolism in male rats involves five male-specific enzymes and three are dominant. Female rats have only one specific P450 enzyme and three dominant isoforms (Lewis, 1996). Humans differ from rats and vary due to lifestyle and pathophysiological states, making interspecies comparisons difficult. Gender differences need to be accounted for when compiling metabolic pathways and data-

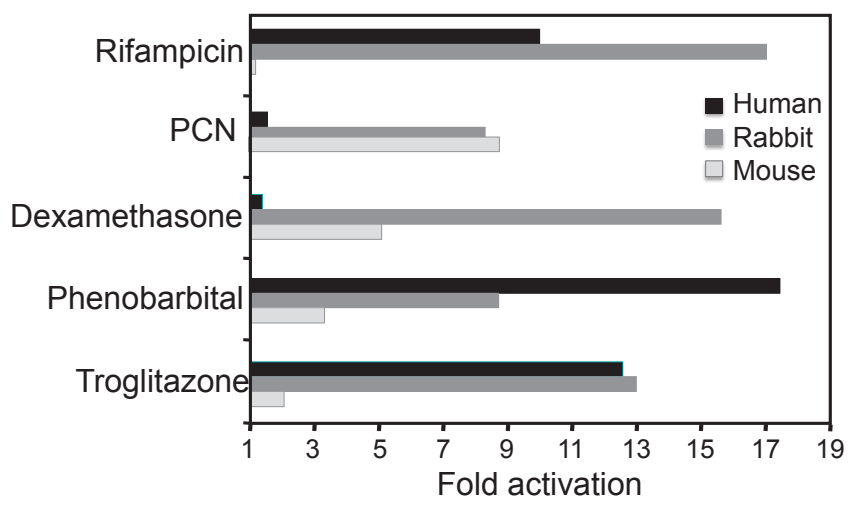

Fig. 3: Example of species differences in receptor activation: Species differential activation of mouse, rabbit and human PXR

M. Jacobs, personal communication 
bases and in all of the projects listed here (short, medium, and long-term).

- A further example of gender differences is the US Centers for Disease Control and Prevention investigation of in vitro Phase I metabolism of BPA in rat and human liver microsomes by using on-line solid-phase extraction-high-performance liquid chromatography-tandem mass spectrometry to identify metabolites (e.g., BPA oxidation products). BPA catechol was the main metabolite of BPA with male rat liver microsomes after incubation of BPA for only $10 \mathrm{~min}$, with a peak after approximately $30 \mathrm{~min}$, which decreased after incubation for 1 hour. Approximately $90 \%$ of the BPA was metabolized after 10 hours and metabolism slowed as the reaction progressed suggesting that no further metabolism occurred. While BPA catechol was also the main oxidized metabolite of BPA with female human liver microsomes, only approximately $10 \%$ of BPA went through this oxidized metabolic pathway (compared with approximately $90 \%$ with male rat microsomes). In female human liver microsomes the peak intensity of BPA catechol did not drop as was observed for BPA treated with male rat microsomes. The metabolic profiles and the kinetics of BPA incubated with female rat and male human microsomes were very similar to those from BPA treated with female human microsomes (Ye et al., 2011).

\subsubsection{Case Studies}

Linkage of in vitro assays for EAS with metabolic pathways to determine adverse outcome pathways

1. An example of how an in vitro system lacking metabolism can be used in concert with methods incorporating metabolism to elucidate the contribution of parent and metabolite(s) to a measured endocrine activity has been demonstrated in Schmieder et al. (2004). Cell-free ER binding assays measured the significantly greater affinity of HPTE for the ER than parent methoxychlor which also had weak, but measurable, affinity for the receptor. Methoxychlor was administered to metabolically competent trout liver slices, and the parent chemical along with all the metabolites formed over time were determined using chemical mass balance. Both Phase I oxidative metabolites and Phase II conjugation products were formed and included in the mass balance. The combined systems were used to demonstrate that the more potent metabolite HPTE was formed in sufficient amounts from the administered parent methoxychlor to account for the majority of VTG induction measured. While sulfate conjugates, first, and glucuronide conjugates, later, were eventually formed from both methoxychlor and HPTE, it was determined that there was sufficient unconjugated HPTE prior to further metabolism to initiate the ER-mediated production of VTG.

2. Bisphenol A (BPA) provides another example of a comparison of its metabolic pathway with observations from in vivo studies. In adult rodents, BPA is most prevalently metabolized via Phase II glucuronidation (reviewed by Van den Berg et al., 2003). The glucuronidated metabolite has decreased affinity for ER $\alpha$ and $\beta$ (Matthews et al., 2001) and is readily excreted in the bile. Glucuronidation also appears to be the main metabolite of BPA in fish. BPA is also hydroxylated, most likely by $\mathrm{P} 450$ enzymes; the resulting metabolites (including 3-hydroxy BPA and BPA o-quinone) have decreased ER binding activity. In the presence of both cytosolic and microsomal S9 fractions, BPA is metabolized to a more active metabolite, 4-methyl-2,4-bis(p-hydroxyphenyl)pent-1-ene (MBP).

In vivo studies have demonstrated enhanced estrogenic effects of BPA in female rats following subcutaneous versus oral exposure. Oral exposure in adults results in first pass metabolism where the majority of BPA is glucuronidated prior to excretion, while subcutaneous exposure allows general circulation of the parent BPA. There were no observed effects on pubertal onset in a multi-generation study or other ER mediated endpoints when BPA was administered orally (Laws et al., 2000; Tyl et al., 2002). More recently, Prins et al. (2011) found that while subcutaneous versus oral exposure affected BPA metabolism, aged male rats given subcutaneous or oral BPA neonatally and testosterone and estrogen implants as adults had heightened susceptibility to estrogen-induced prostate intraepithelial neoplasia. An AOP combined with a metabolic pathway (showing parent and metabolites) for BPA would include all linkages between the initial events associated with the parent chemical and all metabolic products through to either excretion or adverse outcomes. A complete pathway also would include quantitative information regarding the relative kinetics for each step of each critical window of development, and at each life stage (in utero, postnatally, young adult, old adult).

3. A third example demonstrates the use of metabolizing systems and tools to identify endocrine disruptive effects caused by an interference with steroid metabolism. Steroid hormone catalyses are particularly affected by EAS since many xenobiotic-metabolizing enzymes also are involved in steroid hormone catalysis (see review by Swedenborg et al., 2009). For example, phthalates can intervene in the steroid biosynthesis pathway at several steps, including down regulating a rate limiting step, via the steroidogenic acute regulatory protein (StAR), with the delivery of cholesterol into the initial tiers of the steroidogenic pathway, and impacting upon the luteinizing hormone ( $\mathrm{LH})$ inhibition of testosterone which is produced in later pathway steps. Phthalates also are ligands for the PPAR and glucocorticoid receptor (GR) ligands (Fig. 3). They impact downstream events in the testicular Leydig cells via the steroidogenesis pathway causing permanent adverse outcomes such as changes in anogenital distance (AGD). On the other hand, although the isoflavones genistein and daidzein act on some of the same receptors, they do not appear to impact definitively upon the AGD (Fig. 4).

Isoflavones appear to have effects on Leydig cells in rodent models but in non-human primates these do not persist at or after puberty, and there is no impact upon male fertility (Tan et al., 2006). Phthalates also reduce expression of sev- 


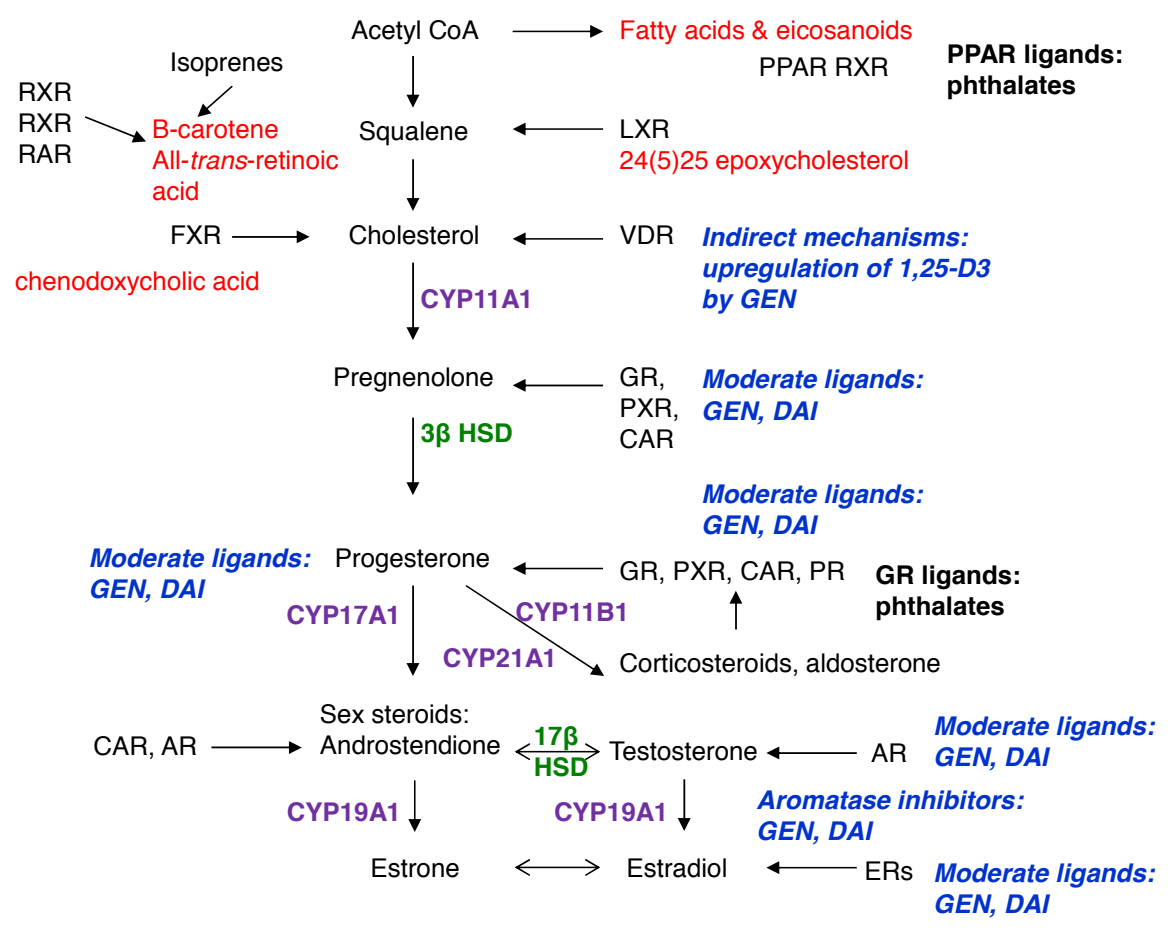

Fig. 4: Effect of the isoflavones genistein (GEN) and daidzein (DAI) and phthalates on receptor and P450 interactions in the steroidogenic pathway

(Adapted from Jacobs et al., 2008). The StAR delivery of cholesterol represents the rate limitation step. The LH inhibition of testosterone is downregulated by phthalates. For the isoflavones, the steroidogenic pathway can be considered to be a biological pathway, as although pathway effects upon Leydig cells are observed, there is no definitive evidence of a permanent impact upon Leydig cells, male fertility, or an in vivo endpoint such as anogenital distance (AGD). However, for phthalates, while neonatal Leydig cell effects also have been observed, the steroidogenic pathway can be perturbed into an AOP, as permanent AGD effects are clearly observed.

eral CYP proteins, the insulin-like peptide hormone-3 gene, and fetal testosterone levels (Rider et al., 2010). The adverse results of phthalate exposure include effects on Leydig cell morphology and function, underdevelopment of the gonadal primordial in both sexes, and inhibition of testes decent in males. In a study performed recently by Desdoits-Lethimonier et al. (2012), where human testis explants and H295R adrenocortical cells were exposed to di-(2-ethylhexyl)phthalate (DEHP) and mono-(2-ethylhexyl)phthalate (MEHP), DEHP was converted in the human testis into the active MEHP resulting in an inhibition of the testosterone production in both cell systems. Using time- and tissue-dependent AOPs for phthalates along with their metabolism maps can help identify and link parent chemical and metabolites with AOP initiating events, intermediate steps, and adverse outcomes (e.g., by identifying the differences in these outcomes of effects upon fetal and adult Leydig cells).

\section{Conclusions}

This paper builds upon recommendations given in OECD DRP 97 (OECD, 2008; Jacobs et al., 2008) for projects to support short, medium, and long-term goals to advance the integration of validated methods for metabolizing systems into EAS/ED assays. Acknowledging the complexity of the issue, this endeavor focuses on building a foundation for the effective use of metabolizing in silico and in vitro approaches not only for the screening and prioritization of EAS, but also for future use in chemical hazard and risk assessment for subsequent risk management. Most recently, the World Health Organization and the United Nations Environment Programme have concluded that little is known about metabolites of EAS/EDs and how such chemicals are transformed in products in their recently published Global assessment of the state-of-the-science of endocrine disruptors conclusions (WHO/UNEP, 2013). WHO/UNEP state that this 
limits our ability to identify and measure EAS/EDs in wildlife, humans and the environment.

This paper demonstrates that tools are readily available to be applied to address this major discrepancy, in the short, medium, and long term.

An ultimate goal is to enhance the international harmonization and acceptance of these methods for assessing metabolism of EAS/EDs into the OECD Conceptual Framework for the screening and testing of EAS. The progress of these projects will need to be revisited on a regular basis, as the information base develops.

\section{Disclaimer}

The use of trade names is for identification only and does not constitute endorsement by the authors, or the US EPA, the European Food Safety Authority, the Humane Society of the United States, or RIKILT-Institute of Food Safety, WUR. This paper and the views expressed are the sole responsibility of the authors. The views expressed are not intended to represent the views of the US EPA, and the European Food Safety Authority, - and may not be considered as an output of the European Food Safety Authority, the Humane Society of the United States, or the RIKILT-Institute of Food Safety, WUR.

\section{References}

Akahori, Y., Nakai, M., Yakabe, Y., et al. (2005). Two-step models to predict binding affinity of chemicals to the human estrogen receptor alpha by three-dimensional quantitative structure-activity relationships (3D-QSARs) using receptorligand docking simulation. SAR QSAR Environ Res 16, 323337.

Andersen, M. E. (2003). Toxicokinetic modeling and its applications in chemical risk assessment. Toxicol Lett 138, 9-27.

Benet, L. Z. and Cummins, C. L. (2001). The drug efflux-metabolism alliance: biochemical aspects. Adv Drug Deliv 50, S3-S11.

Bernauer, U., Vieth, B., Ellrich, R., et al. (1999). CYP2E1dependent benzene toxicity: the role of extrahepatic benzene metabolism. Arch Tox 73, 189-196.

Bernauer, U., Vieth, B., Ellrich, R., et al. (2000). CYP2E1 expression in the bone marrow and its intra- and interspecies variability. Approaches for a more reliable extrapolation from one species to another in the risk assessment of chemicals. Arch Tox 73, 618-624.

Bernauer, U., Ellrich, R., Heinrich-Hirsch, B., et al. (2002). Expression of cytochrome $\mathrm{P} 450$ enzymes in human colon. IARC Sci Publ 156, 487-489.

Bernauer, U., Garritsen, H., Heinrich-Hirsch, B., and GundertRemy, U. (2003). Immunochemical analysis of extrahepatic Cytochrome P450 variability in human leucapheresed samples and its consequences for the risk assessment process. Regul Toxicol Pharmacol 37, 318-327.

Bitsch, N., Dudas, C., Körner, W., et al. (2002). Estrogenic activity of musk fragrances detected by the E-screen assay using human mcf-7 cells. Arch Environ Contam Toxicol 43, 257264.

Bovee, T. F. H., Bor, G., Heskamp, H. H., et al. (2006). Validation and application of a robust yeast estrogen bioassay for the screening of estrogenic activity in animal feed. Food Addit Contam 23, 556-568.

Bovee, T. F. H., Lommerse, J. P. M., Peijnenburg, A. A. C. M., et al. (2008a). A new highly androgen specific yeast biosensor, enabling optimisation of (Q)SAR model approaches. $J$ Steroid Biochem Mol Biol 108, 121-131.

Bovee, T. F. H., Schoonen, W. G. E. J., Hamers, A. R. M., et al. (2008b). Screening of synthetic and plant-derived compounds for (anti)estrogenic and (anti)androgenic activities. Anal Bioanal Chem 390, 1111-1119.

Bovee, T. F. H. and Pikkemaat, M. G. (2009). Bioactivity-based screening of antibiotics and hormones. J Chrom A 1216, 8035-8050.

Bovee, T. F. H., Thevis, M., Hamers, A. R. M., et al. (2010). SERMs and SARMs: detection of their activities with yeast based bioassays. J Steroid Biochem Mol Biol 118, 85-92.

Bull, S., Langezaal, I., Clothier, R., and Coecke S. (2001). A genetically engineered cell-based system for detecting metabolism-mediated toxicity. Altern Lab Anim 29, 703-716.

Carlson, D. L. and Hites, R. A. (2005). Polychlorinated biphenyls in salmon and salmon feed: global differences and bioaccumulation. Environ Sci Technol 39, 7389-7395.

Chalbot, S. and Morfin, R. (2005). Human liver S9 fractions: metabolism of dehydroepiandrosterone, epiandrosterone, and related 7-hydroxylated derivatives. Drug Metab Dispos 33, 563-569.

Clewell, R. A. and Clewell, H. J. (2008) Development and specification of physiologically based pharmacokinetic models for use in risk assessment. Regul Toxicol Pharmacol 50, 129-143.

Coecke, S., Eskes, C., Gartlon, J., et al. (2002). Metabolism and neurotoxicity: The significance of genetically engineered cell lines and new three-dimensional cell cultures. Altern Lab Anim 30, Suppl 2, 115-118.

Coecke, S., Ahr, H., Blaauboer, B. J., et al. (2006). Metabolism: A bottleneck in in vitro toxicological test development. The report and recommendations of ECVAM Workshop 54. Altern Lab Anim 34, 9-84.

Coldham, N. G., Horton, R., Byford, M. F., et al. (2002). Binary screening assay for pro-oestrogens in food: metabolic activation using hepatic microsomes and detection with oestrogen sensitive recombinant yeast cells. Food Addit Contam 19, 1138-1147.

Cunat, S., Rabenoelina, F., Daurès, J. P., et al . (2005). Aromatase expression in ovarian epithelial cancers. J Steroid Biochem Mol Biol 93, 15-24.

Dang, Z., Ru, S., Wang, W., et al. (2011). Comparison of chemicalinduced transcriptional activation of fish and human estrogen receptors: regulatory implications. Toxicol Lett 201, 152-175.

Davies, D. S., George, C. S., Blackwell, E., et al. (1974). Metabolism of terbutaline in man and dog. Br J Clin Pharmacol 1, 129-136. 
de Flora, S., Zanacchi, P., Bennicelli, C., and Arillo, A. (1982). Influence of liver S-9 preparations from rats and rainbow trout on the activity of four mutagens. Toxicol Lett 10, 345-349.

De Graaf, I. A. M., Draaisma, A. L., Schoeman, O., et al. (2007). Cryopreservation of rat precision-cut liver and kidney slices by rapid freezing and vitrification. Cryobiology 54, 1-12.

De Nobel, J. G. and Barnett, J. A. (1991). Passage of molecules through yeast cell walls: a brief assay-review. Yeast 7, 313323.

De Rijke, E., Essers, M. L., Rijk, J. C. W., et al. (in press). In vitro and in vivo metabolism of selective androgen receptor modulators: a validation study. Food Addit Contam.

Desdoits-Lethimonier, C., Albert, O., Le Bizec, B., et al. (2012). Human testis steroidogenesis is inhibited by phthalates. $\mathrm{Hu}$ man Reprod 27, 1451-1459.

Escher, B., Cowan-Ellsberry, C., Dyer, S., et al. (2011). Protein and lipid binding parameters to extrapolate from the in vitro liver S9 metabolic assay to in vivo rainbow trout (Oncorhynchus mykiss) bioaccumulation potential of hydrophobic organic chemicals. Chem Res Toxicol 24, 1134-1143.

Gomez, C. F., Constantine, L., Moen, M., et al. (2011). Ibuprofen metabolism in the liver and gill of rainbow trout, Oncorhynchus mykiss. Bull Environ Contam Toxicol 86, 247-251.

Graham, M. J. and Lake, B. G. (2008). Induction of drug metabolism: Species differences and toxicological relevance. Toxicology 2254, 184-191.

Greally, J. and Jacobs, M. N. (2013). In vitro and in vivo testing methods of epigenomic endpoints for evaluating endocrine disruptors. ALTEX Epub ahead of print.

Gregory, P. A., Lewinsky, R. H., Gardner-Stephen, D. A., and Mackenzie, P. I. (2004). Regulation of UDP glucuronosyltransferases in the gastrointestinal tract. Toxicol Appl Pharmacol 199, 354-363.

Gutendorf, B. and Westendorf, J. (2001). Comparison of an array of in vitro assays for the assessment of the estrogenic potential of natural and synthetic estrogens, phytoestrogens and xenoestrogens. Toxicology 166, 79-89. Erratum in: Toxicology (2011) 280, 179 .

Gutleb, A., Meerts, I. A. T. M., Bergsma, J. H., et al. (2005). T-screen as a tool to identify thyroid hormone receptor active compounds. Environ Toxicol Pharmacol 19, 231-238.

Han, X., Nabb, D. L., Yang, C. H., et al. (2009). Liver microsomes and $\mathrm{S} 9$ from rainbow trout (Oncorhynchus mykiss): comparison of basal-level enzyme activities with rat and determination of xenobiotic intrinsic clearance in support of bioaccumulation assessment. Environ Toxicol Chem 28, 481488.

Harimoto, M., Yamato, M., Hirose, M., et al. (2002). Novel approach for achieving double-layered cell sheets co-culture: overlaying endothelial cell sheets onto monolayer hepatocytes utilizing temperature-responsive culture dishes. $J \mathrm{Bi}$ omed Mater Res 62, 464-470.

Hecker, M., Hollert, H., Cooper, R., et al. (2007). The OECD validation program of the H295R steroidogenesis assay for the identification of in vitro inhibitors and inducers of testosterone and estradiol production. Phase 2: Inter-laboratory pre-validation studies. Environ Science Poll Res, Spec Issue $1,23-30$.

Heringa, M. B., Schreurs, R. H. M., Van Der Saag, P. T., et al. (2004). Toward more useful in vitro toxicity data with measured free concentrations. Environ Sci Technol 38, 62636270 .

Hoogenboom, L. A. P., De Haan, L., Hooijerink, D., et al. (2001). Estrogenic activity of estradiol and its metabolites in the ER-CALUX assay with human T47D breast cells. APMIS 109, 101-107.

Hoogenboom, L. A. P., Van Bruchem, G. D., Sonne, K., et al. (2002). Absorption of a mutagenic metabolite released from protein-bound residues of furazolidone. Environ Toxicol Pharmacol 11, 273-287.

ICCVAM (2003). ICCVAM evaluation of in vitro test methods for detecting potential endocrine disruptors: Estrogen receptor and androgen receptor binding and transcriptional activation assays. NIH Publication No: 03-4503.

Jacobs, M. N., Covaci, A., and Schepens. P. (2002). Investigation of selected persistent organic pollutants in salmon (Salmo Salar), salmon feed and fish oil components of salmon feeds. Environ Sci Technol 36, 2797-2805.

Jacobs, M. N., Janssens, W., Combes, R., et al. (2008). The use of metabolising systems for in vitro testing of endocrine disruptors. Curr Drug Metab 9, 796-826.

Johanning, K.,Hancock, G.,Escher, B., et al. (2012). Assessment of metabolic stability using the rainbow trout (Oncorhynchus mykiss) liver S9 fraction. Curr Prot, 14.10.1-14.10.28.

Kawai, S., Kobayashi, M., and Kaneko, H. (2003). Topic 4.11: Effects of endocrine active substances in wildlife species: Genetic, biochemical, and physiological factors in variable susceptibility to endocrine disruptors. Pure Appl Chem 75, 2335-2341.

Kolanczyk, R. C., Schmieder, P., Jones, W. J., et al. (2012). MetaPath: An electronic knowledgebase for collating, exchanging and analyzing case studies of xenobiotic metabolism. Regul Tox Pharm 63, 84-96.

Krul, C., Luiten-Schuite, A., Baandagger, R., et al. (2000). Application of a dynamic in vitro gastrointestinal tract model to study the availability of food mutagens, using hereocyclic aromatic amines as model compounds. Food Chem Toxicol 38, 783-792.

Kuuranne, T., Leinonen, A., Schänzer, W., et al. (2008). Arylpropionamide-derived selective androgen receptor modulators: liquid chromatography-tandem mass spectrometry characterization of the in vitro synthesized metabolites for doping control purposes. Drug Metab Dispos 36, 571-581.

Lachmann, A., Xu, H., Krishnan, J., et al. (2010). ChEA: transcription factor regulation inferred from integrating genomewide ChIP-X experiments. Bioinformatics 26, 2438-2444.

Lamb, J., Crawford, E. D., Peck, D., et al. (2006). The Connectivity Map: using gene-expression signatures to connect small molecules, genes, and disease. Science 313, 1929-1935.

Laws, S. C., Carey, S. A., Ferrell, J. M., et al. (2000). Estrogenic activity of octylphenol, nonylphenol, bisphenol A and methoxychlor in rats. Toxicol Sci 54, 154-167. 
Lewis, D. F. V. (1996). Cytochromes P450: Structure, Function and Mechanism. London, UK: Taylor and Francis.

Li, J., Chen, M., Wang, Z., et al. (2011). Analysis of environmental endocrine disrupting activities in wastewater treatment plant effluents using recombinant yeast assays incorporated with exogenous metabolic activation system. Biomed Environ Sci 24, 132-139.

Matthews, J. B., Twomey, K., and Zacharewski, T. R. (2001). In vitro and in vivo interactions of bisphenol A and its metabolite, bisphenol A glucuronide, with estrogen receptors alpha and beta. Chem Res Toxicol 14, 149-157.

Mekenyan, O. G., Dimitrov, S. D., Pavlov, T. S., and Veith, G. D. (2004). A systematic approach to simulating metabolism in computational toxicology. I. The TIMES heuristic modelling framework. Curr Pharm Des 10, 1273-1293.

Mitea, C., Havenaar, R., Drijfhout, J. W., et al. (2008). Efficient degradation of gluten by a prolyl endoprotease in a gastrointestinal model: implications for celiac disease. Gut 57, 2532 .

Morohoshi, K., Yamamoto, H., Kamata, R., et al. (2005). Estrogenic activity of 37 components of commercial sunscreen lotions evaluated by in vitro assays. Toxicol In Vitro 19, 457469.

NAS - National Academy of Science (2007). Toxicity Testing in the $21^{\text {st }}$ Century: A Vision and a Strategy. Washington, DC, USA: National Academies Press.

Ochsner, S. A., Steffen, D. L., Hilsenbeck, S. G., et al. (2009). GEMS (Gene Expression MetaSignatures), a web resource for querying meta-analysis of expression microarray datasets: 17beta-estradiol in MCF-7 cells. Cancer Res 69, 23-26.

OECD (1996). OECD Guideline for Testing of Chemicals. Test No. 422: Combined repeated dose toxicity study with the reproduction/developmental toxicity screening test. http:// www.oecd-ilibrary.org/environment/oecd-guidelines-for-thetesting-of-chemicals-section-4-health-effects_20745788

OECD (2001). OECD Guideline for Testing of Chemicals. Test No 416: Two-generation reproduction toxicity. http:// www.oecd-ilibrary.org/environment/test-no-416-twogeneration-reproduction-toxicity_9789264070868en;jsessionid=2b9562w68u34r.x-oecd-live-02

OECD (2005). Guidance Document: The validation and international acceptance of new or updated test methods for hazard assessment. Series on Testing and Assessment, No. 34. OECD, Paris. http://search.oecd.org/ officialdocuments/displaydocumentpdf/?cote $=$ env $/ \mathrm{jm} /$ mono(2005)14\&doclanguage $=$ en

OECD (2006). Detailed Review Paper: Thyroid Hormone Disruption Assays. OECD Series on Testing and Assessment, No. 57. Organisation for Economic Cooperation and Development, Paris.

OECD (2008). Detailed Review Paper: The Use of Metabolising systems for In vitro Testing of Endocrine Disruptors. OECD Series on Testing and Assessment, No. 97. Organisation for Economic Cooperation and Development, Paris.

OECD (2009). Report of the Expert Consultation to Evaluate an Estrogen Receptor Binding Affinity Model for Hazard
Identification. Series on Testing and Assessment, No. 111. August 21, 2009. ENV/JM/MONO(2009)33. http://search. oecd.org/officialdocuments/displaydocumentpdf/?cote=env/ $\mathrm{jm} / \mathrm{mono}(2009) 33 \&$ doclanguage $=\mathrm{en}$

OECD (2010). Detailed Review Paper: Environmental endocrine disruptor screening: the use of estrogen and androgen receptor binding and transactivation assays in fish. OECD Series on Testing and Assessment, No. 135. Organisation for Economic Cooperation and Development, Paris. http://search. oecd.org/officialdocuments/displaydocumentpdf/?cote=env/ $\mathrm{jm} / \mathrm{mono}(2010) 34 \&$ doclanguage $=\mathrm{en}$

OECD (2011a). OECD Guideline for Testing of Chemicals. Test No. 456: H295R Steroidogenesis Assay. http://www.oecdilibrary.org/environment/test-no-456-h295r-steroidogenesisassay_9789264122642-en;jsessionid=2b9562w68u34r.xoecd-live-02

OECD (2011b). OECD Guideline for Testing of Chemicals. Test No. 443: Extended One-Generation Reproductive Toxicity Study. http://www.oecd-ilibrary.org/environment/ test-no-443-extended-one-generation-reproductive-toxicitystudy_9789264122550-en;jsessionid=2b9562w68u34r.xoecd-live-02

OECD (2012a). Guidance Document on Standardised Test Guidelines for Evaluating Chemicals for Endocrine Disruption. Series onTesting and Assessment,No.150,OECD,Paris.http://search. oecd.org/officialdocuments/displaydocumentpdf/?cote=env/ $\mathrm{jm} / \mathrm{mono}(2012) 22 \&$ doclanguage $=\mathrm{en}$

OECD (2012b). OECD Guideline for Testing of Chemicals Test No. 455: Performance-based test guideline for stably transfected transactivation in vitro assays to detect estrogen receptor agonists. OECD, Paris. http://www.oecd-ilibrary. org/environment/test-no-455-performance-based-testguideline-for-stably-transfected-transactivation-in-vitroassays-to-detect-estrogen-receptor-agonists_97892641 85388-en;jsessionid=2b9562w68u34r.x-oecd-live-02

OECD (2012c). OECD Guideline for Testing of Chemicals Test No. 457: BG1Luc estrogen receptor transactivation test method for identifying estrogen receptor agonists and antagonists. http://www.oecd-ilibrary.org/environment/ test-no-457-bg1luc-estrogen-receptor-transactivation-testmethod-for-identifying-estrogen-receptor-agonists-and-an tagonists_9789264185395-en;jsessionid=2b9562w68u34r.xoecd-live-02

OECD (2012d). Detailed Review Paper: The State of the Science on Novel In vitro and In vivo Screening and Testing Methods and Endpoints for Evaluating Endocrine Disruptors, Series on Testing and Assessment, No. 178, OECD, Paris.

Oomen, A. G., Rompelberg, C. J. M., Bruil, M. A., et al. (2003). Development of an in vitro digestion model for estimation of bioaccessibility of soil contaminants. Arch Environ Contam Toxicol 44, 281-287.

Pagliara, P., Carlà, E. C., Caforio, S., et al. (2003). Kupffer cells promote lead nitrate-induced hepatocyte apoptosis via oxidative stress. Comp Hepatol 2, 8 .

Peyret, T., Poulin, P., and Krishnan, K. (2010). A unified algorithm for predicting partition coefficients for PBPK modeling 
of drugs and environmental chemicals. Toxicol Appl Pharmacol 249, 197-207.

Plant, N. (2004). Strategies for using in vitro screens in drug metabolism. Drug Discov Today 9, 328-336.

Prins, G. S., Ye, S. H., Birch, L., et al. (2011). Serum bisphenol A pharmacokinetics and prostate neoplastic responses following oral and subcutaneous exposures in neonatal SpragueDawley rats. Reprod Toxicol 31, 1-9.

Punt, A., Schiffelers, M. J., Horbach, J. G., et al. (2011). Evaluation of research activities and research needs to increase the impact and applicability of alternative testing strategies in risk assessment practice. Regul Toxicol Pharmacol 61, 105-114.

Rasmussen, T. H. and Nielsen, J. B. (2002). Critical parameters in the MCF-7 cell proliferation bioassay (E-Screen). Biomarkers 7, 322-336.

Rasmussen, T. H., Nielsen, F., Andersen, H. R., et al. (2003). Assessment of xenoestrogenic exposure by a biomarker approach: application of the E-Screen bioassay to determine estrogenic response of serum extracts. Environ Health 15, 12.

Rider, C. V., Furr, J. R., Wilson, V. S., and Gray, L. E. Jr. (2010). Cumulative effects of in utero administration of mixtures of reproductive toxicants that disrupt common target tissues via diverse mechanisms of toxicity. Int J Androl 33, 443-462.

Rijk, J. C. W., Bovee, T. F. H., Groot, M. J., et al. (2008). Evidence of the indirect hormonal activity of prohormones using liver S9 metabolic bioactivation and an androgen bioassay. Anal Bioanal Chem 392, 417-425.

Rijk, J. C. W., Bovee, T. F. H., Peijnenburg, A. A. C. M., et al. (2012). Bovine liver slices: a multifunctional in vitro model to study the prohormone dehydroepiandrosterone (DHEA). Toxicol In Vitro 26, 1014-1021.

Roy, P., Yu, L. J., Crespi, C. L., and Waxman, D. J. (1999). Development of a substrate-activity based approach to identify the major human liver P-450 catalysts of cyclophosphamide and ifosfamide activation based on cDNA-expressed activities and liver microsomal P-450 profiles. Drug Metab Dispos 27, 655-666.

Scherrer, R., Louden, L., and Gerhardt, P. (1974). Porosity of the yeast cell wall and membrane. J Bacteriol 118, 534-540.

Schmieder, P., Tapper, M., Denny, J., et al. (2004). Use of trout liver slices to enhance mechanistic interpretation of ER binding for cost-effective prioritization of chemicals within large inventories. Environ Sci Technol 38, 6333-6342.

Setchell, K. D. and Clerici, C. (2010). Equol: pharmacokinetics and biological actions. J Nutr 140, 1363S-1368S.

Shen, D. D., Kunze, K. L., and Thummel, K. E. (1997). Enzyme-catalyzed processes of first-pass hepatic and intestinal drug extraction. Adv Drug Deliv Rev 27, 99-127.

Soto, A. M., Sonnenschein, C., Chung, K. L., et al. (1995). The E-SCREEN assay as a tool to identify estrogens: an update on estrogenic environmental pollutants. Environ Health Perspect 103, Suppl 7, 113-122.

Sung, E., Turan, N., Ho, P. W., et al. (2012). Detection of endocrine disruptors - from simple assays to whole genome scanning. Int J Androl 35, 407-414.
Swedenborg, E., Rüegg, J., Mäkelä, S., and Pongratz, I. (2009). Endocrine disruptive chemicals: mechanisms of action and involvement in metabolic disorders. J Mol Endocrinol 43, 1-10.

Swart, J. C. and Pool, E. J. (2009). Development of a bio-assay for estrogens using estrogen receptor alpha gene expression by MCF7 cells as biomarker. J Immunoassay Immunochem 30, 150-165.

Tan, K. A., Walker, M., Morris, K., et al. (2006). Infant feeding with soy formula milk: effects on puberty progression, reproductive function and testicular cell numbers in marmoset monkeys in adulthood. Hum Reprod 21, 896-904.

Taxvig, C., Olesen, P. T., and Nellemann, C. (2011). Use of external metabolizing systems when testing for endocrine disruption in the T-screen assay. Toxicol Appl Pharmacol 250, 263-269.

Tegnér, K., Nilsson, H. T., Persson, C. G., et al. (1984). Elimination pathways of terbutaline. Eur J Respir Dis, Suppl 134, 93-100.

Tyl, R. W., Myers, C. B., Marr, M. C., et al. (2002). Three-generation reproductive toxicity study of dietary bisphenol $\mathrm{A}$ in CD Sprague-Dawley rats. Toxicol Sci 68, 121-146.

US EPA - United States Environmental Protection Agency (2009). Endocrine Disruptor Screening Program (EDSP) Tier 1 battery. http://epa.gov/endo/pubs/assayvalidation/tier1battery.htm

US EPA FIFRA SAP (2009a). An effects-based expert system to predict estrogen receptor binding affinity for food use inert ingredients and antimicrobial pesticides: Application in a prioritization scheme for endocrine disruptor screening, meeting materials. http://www.regulations. gov/\#! docketDetail;D=EPA-HQ-OPP-2009-0322

US EPA FIFRA SAP (2009b). An effects-based expert system to predict estrogen receptor binding affinity for food use inert ingredients and antimicrobial pesticides: Application in a prioritization scheme for endocrine disruptor screening, meeting minutes. http://www.epa.gov/scipoly/sap/meetings/2009/ august/082509minutes.pdf

US EPA FIFRA SAP (2013). Meeting report of the Federal Insecticide, Fungicide, and Rodenticide Act (FIFRA) Scientific Advisory Panel (SAP). http://www.epa.gov/scipoly/sap

Valerio, L. G. and Long, A. (2010). The in silico prediction of human-specific metabolites from hepatotoxic drugs. Curr Drug Discov Technol 7, 170-187. http://www.lhasalimited.org

Van den Berg, M., Sanderson, T., Kurihara, N., and Katayama, A. (2003). Topic 2.7: Role of metabolism in the endocrinedisrupting effects of chemicals in aquatic and terrestrial systems. Pure Appl Chem 75, 1917-1932.

van der Burg, B., Winter, R., Weimer, M., et al. (2010). Optimization and prevalidation of the in vitro ERalpha CALUX method to test estrogenic and antiestrogenic activity of compounds. Reprod Toxicol 30, 73-80.

Van der Kerkhof, E. G., Ungell, A. B., Sjoberg, A. K., et al. (2006). Innovative methods to study human intestinal drug metabolism in vitro: precision-cut slices compared with Uss- 
ing Chamber preparations. Drug Metab Dispos 34, 18931902.

Van der Rest, M.E., Kamminga, A. H., Nakano, A., et al. (1995). The plasmamembrane of Saccharomyces cerevisae: structure, function, and biogenesis. Microbiol Rev 59, 304-322.

Versantvoort, C. H. M., Oomen, A. G., Van de Kamp, E., et al. (2005). Applicability of an in vitro digestion model in assessing the bioaccessibility of mycotoxins from food. Food Chem Toxicol 43, 31-40.

Verwei, M., Van den Berg, H., Havenaar R., and Groten, J. P. (2005). Effect of folate-binding protein on intestinal transport of folic acid and 5-methyltetrahydrofolate across caco-2 cells. Eur J Nutr 44, 242-249.

Villalobos, M., Olea, N., Brotons, J. A., et al. (1995) The Escreen assay: a comparison of different MCF7 cell stocks. Environ Health Perspect 103, 844-850.

Volotinen, M., Turpeinen, M., Tolonen, A., et al. (2007). Timolol metabolism in human liver microsomes is mediated principally by CYP2D6. Drug Metab Dispos 35, 1135-1141.

Wagner, J., Jiang, L., and Lehmann, L. (2008). Phytoestrogens modulate the expression of 17alpha-estradiol metabolizing enzymes in cultured MCF-7 cells. Adv Exp Med Biol 617, 625-632.

Wagner, M. and Oehlmann, J. (2011). Endocrine disruptors in bottled mineral water: estrogenic activity in the E-Screen. $J$ Steroid Biochem Mol Biol 127, 128-135.

Wang, S., Aarts, J. M. M. J. G., Evers, N. M., et al. (2012). Proliferation assays for estrogenicity testing with high predictive value for the in vivo uterotrophic effect. J Steroid Biochem Mol Biol 128, 98-106.

Waring, R. H., Ramsden, D. B., Jarratt, P. B., and Harris, R. M. (2012). Biomarkers of endocrine disruption: cluster analysis of effects of plasticisers on Phase 1 and Phase 2 metabolism of steroids. Int J Andrology 35, 415-423.

Weiss, T. S., Jahn, B., Cetto, M., et al. (2002). Collagen sandwich culture affects intracellular polyamine levels of human hepatocytes. Cell Prolif 35, 257-267.

Westerink, W. M. A. and Schoonen, W. G. E. J. (2007). Phase II enzyme levels in HepG2 cells and cryopreserved primary human hepatocytes and their induction in HepG2 cells. Toxicol In Vitro 21, 1592-1602.

Weybridge Conference (1996). European workshop on the impact of endocrine disrupters on human health and wildlife.
Report of proceedings, EUR 17549, DG XII of the European Commission.

WHO - World Health Organization (2002). Global assessment of the state-of-the-science of endocrine disruptors. Eds: Damstra, T., Barlow, S., Bergman, A., Kavlock, R. and Van der Kraak, G., WHO/PCS/EDC/02.2, World Health Organisation, Geneva. 180 pp.

WHO/UNEP - World Health Organization/United Nations Environment Programme (2013). State of the science of endocrine disrupting chemicals - 2012. A. Bergman, J. J. Heindel, S. Jobling, K. A. Kidd, and R. T. Zoeller (eds.). World Health Organisation, Geneva. 296 pp. http://www.who.int/media centre/news/releases/2013/hormone_disrupting_20130219/ en/index.html

Wiebel, F. J., Andersson, T. B., Casciano, D. A., et al. (1997). Genetically engineered cell lines: Characterisation and applications in toxicity testing, the report and recommendations of ECVAM Workshop 26. Altern Lab Anim 25, 625-639.

Wilson, C. J., Brain, R. A., Sanderson, H., et al. (2004). Cloning and in vitro expression and characterization of the androgen receptor and isolation of estrogen receptor $\mathrm{r}$ from the fathead minnow (Pimephales promelas). Environ Sci Technol 38, 6314-6321.

Ye, X., Zhou, X., Needham, L. L., and Calafat, A. M. (2011). In-vitro oxidation of bisphenol A: Is bisphenol A catechol a suitable biomarker for human exposure to bisphenol A? Anal Bioanal Chem 399, 1071-1079.

\section{Acknowledgments}

The authors acknowledge the helpful discussion, review, and input on the first drafts of this paper by the members of the OECD VMG-NA.

\section{Correspondence to}

Miriam N. Jacobs, PhD

Scientific Committee and Emerging Risks Unit

European Food Safety Authority

Via Carlo Magno 1/A

Parma 43126

Italy

e-mail: Miriam.JACOBS@efsa.europa.eu 